Check for updates

Cite this: Chem. Sci., 2019, 10, 7009

๑ All publication charges for this article have been paid for by the Royal Society of Chemistry

Received 26th May 2019

Accepted 4th June 2019

DOI: 10.1039/c9sc02557j

rsc.li/chemical-science

\section{A general concept for the introduction of hydroxamic acids into polymers $\uparrow$}

\author{
Tobias Johann, ${ }^{a}$ Jennifer Keth, ${ }^{a}$ Matthias Bros ${ }^{b}$ and Holger Frey (DD *a
}

Hydroxamic acids (HA) form stable complexes with a large variety of metal-ions, affording hydroxamates with high complexation constants. Hydroxamic acid moieties play a crucial role in the natural iron metabolism. In this work, 1,4,2-dioxazoles linked to a hydroxyl group are introduced as key compounds for the installation of hydroxamic acids at synthetic polymers in well-defined positions. A general synthetic scheme is developed that gives access to a series of novel functional key building blocks that can be universally used to obtain hydroxamic acid-based monomers and polymers, for instance as protected HA-functional initiators or for the synthesis of a variety of novel HA-based monomers, such as epoxides or methacrylates. To demonstrate the excellent stability of the dioxazole-protected hydroxamic acids, direct incorporation of the dioxazole-protected hydroxamic acids into polyethers is demonstrated via oxyanionic polymerization. Convenient subsequent deprotection is feasible under mild acidic conditions. $\alpha$-Functional HA-polyethers, i.e. poly ethylene glycol, polypropylene glycol and polyglycerol based on ethylene oxide, propylene oxide and ethoxy ethyl glycidyl ether, respectively are prepared with low dispersities $(<1.2)$ in the molecular weight range of 1000 to $8500 \mathrm{~g} \mathrm{~mol}^{-1}$. Water-soluble hydroxamic acid functional poly(ethylene glycol) (HA-PEG) is explored for a variety of biomedical applications and surface coating. Complexation of $\mathrm{Fe}(\mathrm{II})$ ions, coating of various metal surfaces, enabling e.g., solubilization of $\mathrm{FeO}_{x}$ nanoparticles by HA-PEGs, are presented. No impact of the polyether chain on the chelation properties was observed, while significantly lower anti-proliferative effects were observed than for deferoxamine. HA-PEGs show the same complexation behavior as their low molecular weight counterparts. Hydroxamic acid functional polymers are proposed as an oxidatively stable alternative to the highly established catechol-based systems.

\section{Introduction}

In the last two decades, biomimetic materials with chelating and interface-adhesive moieties, such as catechols or their derivatives, have been investigated intensely. ${ }^{\mathbf{1 , 2}}$ Particularly catechol-bearing polymers that mimic mussel-foot proteins containing dopamine have attracted broad interest, as their outstanding adhesive properties enable strong interaction with almost every surface., ${ }^{\mathbf{1 , 3} 4}$ Numerous applications like selfhealing hydrogels, surface coatings for anti-fouling purposes or the formation of supramolecular networks, especially by combination of chelating moieties with polymers, have been demonstrated. ${ }^{5}$ In two of our previous works we focused on the direct incorporation of catechols into polyethers via anionic polymerization. Polymers bearing a single catechol moiety were

${ }^{a}$ Institute of Organic Chemistry, Johannes Gutenberg University, Duesbergweg 10-14, 55128 Mainz, Germany. E-mail: hfrey@uni-mainz.de

${ }^{b}$ Department of Dermatology, University Medical Center of the Johannes Gutenberg University Mainz, Langenbeckstrasse 1, 55131 Mainz, Germany

$\dagger$ Electronic supplementary information (ESI) available: NMR, IR, SEC, LCST and mass spectroscopy characterization, cell toxicity and proliferation assay data. See DOI: $10.1039 / \mathrm{c} 9 \mathrm{sc} 02557 \mathrm{j}$ used for the stabilization of MnO nanoparticles in solution. Via a tailored catechol epoxide monomer, multiple units were introduced along the polyether backbone enabling gelation upon iron(III) addition. ${ }^{6}$ However, most catechols are unstable under aqueous conditions and are known to crosslink via oxidative coupling. This irreversible reaction leads to highly toxic Michael systems. Even though no Michael adduct of amines and the quinone structure was found in studies of Deming et al., the quinone structures lead to cross-linked materials, impeding the reversibility of the formed complexes. ${ }^{4}$ Nevertheless, catechols are ubiquitous in nature as one of two moieties to form so called siderophores (greek: "iron carrier"). The second prominent class of siderophores relies on hydroxamic acids. These $N$-hydroxylated amides are capable of forming stable complexes with a large variety of metal-ions, affording hydroxamates with complexation constants in the range of $\log K=28$ for tris-complexes to $\log K=20$ for biscomplexes. $^{7,8}$ Their binding affinity to metals is generally 7 magnitudes higher compared to carboxylic acids due to the formation of a five membered ring. ${ }^{9}$ In nature this class of siderophores is essential to solubilize water-insoluble iron oxide, thus increasing the bioavailability of this key element. ${ }^{\mathbf{1 0}}$ 
More than 42 different metal-hydroxamate complexes including (but not limited to) $\mathrm{Fe}(\mathrm{III}), \mathrm{Mn}$ (II), $\mathrm{Zn}$ (II), $\mathrm{Cu}$ (II) and $\mathrm{Ni(II)}$ are currently known. ${ }^{7,8,11}$ In contrast to catechols, hydroxamic acids are stable under physiological conditions and neither undergo oxidation nor crosslinking. They show similar $\mathrm{p} K_{\mathrm{s}}$-values in the range of $7-9 .^{12}$

While there are only few studies on hydroxamic acids in the field of synthetic polymers, they are well established in the therapy of iron overload diseases or as potent inhibitors for histone deacetylases that are mostly associated with cancer development. ${ }^{13}$ Early efforts to combine hydroxamic acids with polymers were patented in 1942 by Du Pont. ${ }^{14}$ First systematic studies were reported by Winston et al. in the late 1970s. In these works, poly(hydroxamic acids) were synthesized by polymer modification reaction of poly(methacrylate)-based active esters with hydroxylamine derivatives. ${ }^{15,16}$

A variety of applications was proposed for polymers containing hydroxamic acids. Due to their strong complexation of metal-ions the most prominent application is their use as ionexchange resins or for waste-water treatment. ${ }^{17-19}$ In other works, poly(hydroxamic acid)s were used for the separation of rare earth metals. ${ }^{17,19}$ Furthermore, application of poly(hydroxamic acid)s as starting material for peptide synthesis and as resin-bound acryl transfer reagent was reported. ${ }^{20}$ We emphasize that in all published reports the hydroxamic acid containing polymers were synthesized via polymer modification (post-polymerization) of carbonyl compounds, such as esters or amides with hydroxylamine. However, this approach inevitably leads to limited conversion due to the harsh reaction conditions, which is an obstacle for many applications, particularly for medical purposes. ${ }^{21}$ Nome and coworkers showed that the conversion of polyamides to hydroxamic acids by reaction with hydroxylamine leads to an alternating copolymer with both carboxylic and hydroxamic acids due to neighboring effects. ${ }^{22}$ In recent works Kizhakkedathu et al. reported conjugates of hyperbranched polyethers with deferoxamine (DFO, Desferal), a biologically produced tris-hydroxamic acid used for the therapy of iron overload diseases. ${ }^{23}$ These modified polyethers improved the plasma half time of deferoxamine 500-fold. This enhancement in pharmacokinetic properties impressively demonstrates the potential of hydroxamic acid functional polyethers. Besides the medical use of hydroxamic acids for the therapy of iron overload diseases, structures analogous to biological siderophores like desferrichrome containing multiple hydroxamic acids have been investigated as potent $\operatorname{Zr}(\mathrm{Iv})$ chelators for PET imaging. ${ }^{24}$ Radical polymerization of hydroxamic acid functional methacrylates was shown to proceed with incomplete conversion due to radical transfer to the hydroxamic acid moiety. ${ }^{25}$ Hence, the attachment of hydroxamic acids to synthetic polymer architectures via polymer modification or direct radical polymerization represents a challenge, and new strategies based on HA-based building blocks are required.

In this work we describe a systematic approach for the introduction of hydroxamic acids to polymers via tailored hydroxyl functional 1,4,2-dioxazoles. The concept presented can be applied to different classes of monomers and initiators that are amenable to both radical and anionic polymerization. Polymers from epoxide and methacrylate based monomers utilizing the 1,4,2-dioxazole group to introduce multiple hydroxamic acids along the polymer backbone are currently in progress and will reported in forthcoming works. At the example of the harsh conditions of the anionic ring opening polymerization, we demonstrate in the second part of this work the introduction of precisely one hydroxamic acid end group in polyethers, in particular in poly(ethylene glycol), aiming at a narrow molecular weight distribution for medical application, combined with a well-defined polymer structure, enabling investigation of the structure-related properties of hydroxamic acid functional polyethers. We aim at combining the chelating properties of hydroxamic acids with PEG as the current "gold standard" of biocompatible, water-soluble polymers. ${ }^{26}$ Based on this work we propose hydroxamic acids as an oxidation-stable alternative to catechols in the field of materials science.

\section{Results and discussion}

\section{A. Molecular construction kit for hydroxamic acid synthons based on 1,4,2-dioxazole protected functional structures}

For the introduction of hydroxamic acids to polymers we initially screened various polymer modification approaches. Typically hydroxamic acids are introduced at the end of a synthetic sequence, e.g. at a polymer structure by reaction with hydroxylamine or its protected derivatives, leading to incomplete functionalization with many side products. This strategy also lacks general applicability. ${ }^{22,27}$ Hence, for the introduction of hydroxamic acids into polymers, we decided to avoid postpolymerization processes with hydroxylamine as a common option for functionalization, as they are restricted to a particular polymer system and thus limit the universal character for further applications. To establish functional groups at welldefined sites during chain-growth polymerization either (i) functional initiators (ii) functional monomers or (iii) functional termination reagents can be employed. Protected hydroxyl functional hydroxamic acids were developed for this approach, featuring both a protected hydroxamic acid to ensure stability during polymerization and a hydroxyl group for further transformation or use as initiators or monomers.

The hydroxyl moiety can be conveniently transformed to methacrylate monomers and epoxide monomers (Scheme 2), for instance glycidyl ethers. Additionally, the hydroxyl group can directly be used in anionic ring opening polymerization (AROP) as an initiator for epoxide or lactide polymerization, thus creating a platform for both radical as well as anionic polymerization (Scheme 1). In this work we place the focus on the use of hydroxyl functional initiators for AROP of common epoxides (EO, PO, glycidyl ethers) to combine the hydroxamic acids with medically relevant polymers. Multifunctional polyethers from hydroxamic acid functional epoxides, as well as methacrylate based HA copolymers are currently in progress and will be reported in forthcoming works.

Selection and optimization process of the protected hydroxamic acid initiator. Based on the abovementioned prerequisites, we focused on (i) the selection of suitable 


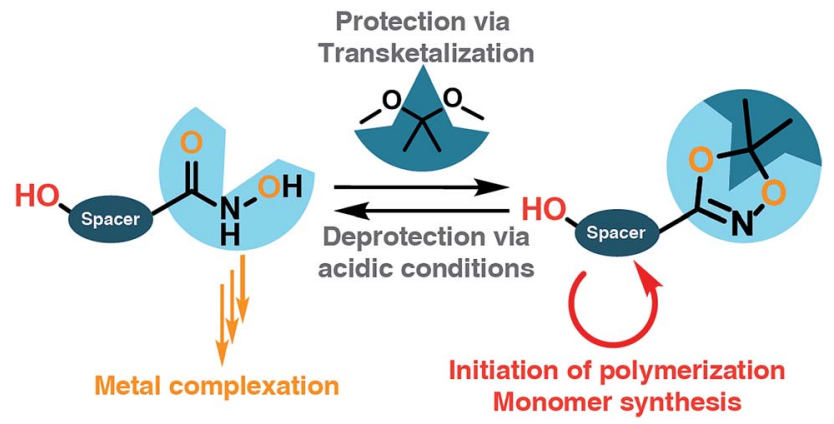

Scheme 1 General concept for the introduction of hydroxamic acids at polymers: the hydroxamic acid is protected in the 1,4,2-dioxazole group via transketalization. The remaining free hydroxyl group can be used as a starting point either for monomer synthesis (methacrylates, epoxides) or as an initiator for anionic ring opening polymerization. After acidic treatment the 1,4,2-dioxazole group is cleaved to release the free hydroxamic acid for metal complexation.

functional hydroxamic acids and (ii) the optimization of protection and deprotection procedures to ensure stability of the hydroxamic acid during the polymerization process, while maintaining the capability of mild and facile deprotection and release of the functional moiety.

Choice of suitable hydroxyl functional hydroxamic acids. No compound containing a hydroxyl group combined with a hydroxamic acid, except for salicylhydroxamic acid and N,4dihydroxybenzamide (Scheme 2, compound 2a), is currently commercially available. Salicylhydroxamic acid is not suitable
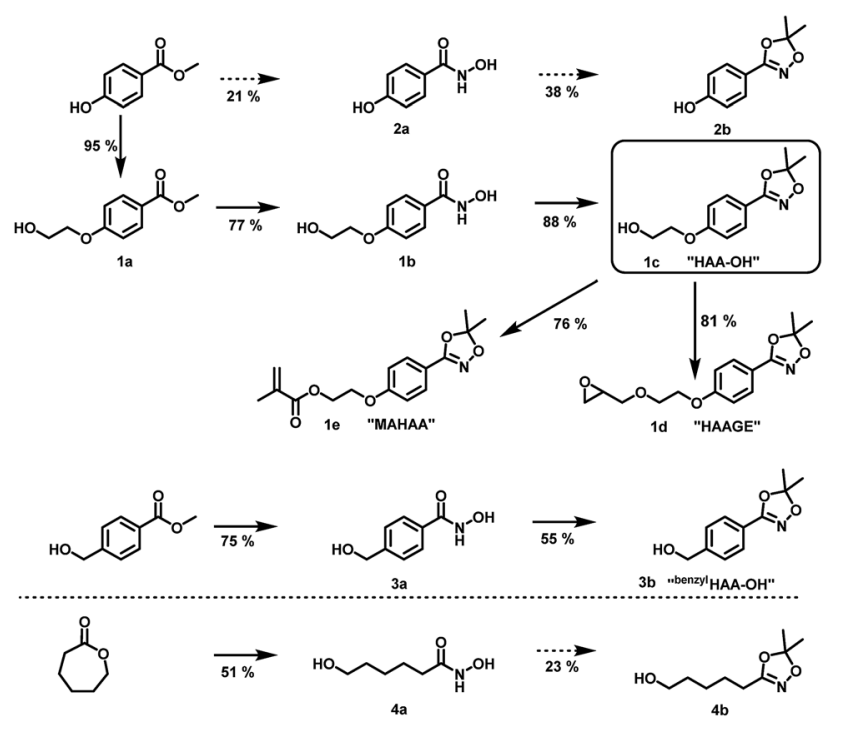

Scheme 2 Preparation of hydroxyl functional hydroxamic acids, their corresponding protected 1,4,2-dioxazole form and further transformation to monomers (1d, 1e) developed in this work. See ESI Scheme $\mathrm{S} 1 \uparrow$ for additional reactions with $\mathrm{C}_{3}$ and $\mathrm{C}_{4}$ aliphatic spacers. Conditions for the preparation of hydroxamic acids (1b, 2b, 3a, 4a): $\mathrm{NH}_{2} \mathrm{OH} / \mathrm{KOH} / \mathrm{MeOH}$ or water, RT; conditions for the preparation of 1,4,2-dioxazoles: 2,2-dimethoxy propane or 2,2-diethoxy propane, CSA, DCM, RT. For detailed synthesis description see experimental section. for facile conversion to 1,4,2-dioxazoles due to the close proximity of the hydroxyl group in ortho position to the hydroxamic acid moiety, prohibiting the synthesis via scalable processes. ${ }^{28}$ Hence, N,4-dihydroxybenzamide (2a) was chosen as a first candidate for the preparation of the desired initiators. Even though $N$,4-dihydroxybenzamide (2a) is available at specialized chemical distributors, albeit its high price impedes larger scale synthesis of the 1,4,2-dioxazole. The preparation of $2 \mathbf{a}$ is known in literature, but typically multistep syntheses or costly protected hydroxylamine derivatives are employed. ${ }^{29}$

To maintain a scalable process, we focused on preparation methods for hydroxamic acids based on esters and hydroxylamine, due to the absence of protecting group chemistry, excellent commercial availability and the preparation in one step. Hence, para-methyl paraben was chosen as a starting material for the synthesis of $2 \mathrm{a}$ via nucleophilic cleavage of the ester bond by hydroxylamine (See ESI Fig. S5a-f $\uparrow$ for NMR and IR characterization data). Unfortunately, all attempts to synthesize the corresponding hydroxamic acid led to low yields with many side products and thus troublesome purification. This is attributed to the deprotonation of the phenolic hydroxyl group, leading to a delocalized negative charge within the aromatic system. Hence, nucleophilic attack by hydroxylamine to form the hydroxamic acid is highly obstructed. To overcome this issue, we introduced an ethylene glycol $\mathrm{C}_{2}$ spacer, which enabled facile synthesis of the hydroxyl functional hydroxamic acid ("HA-OH", 1b) in high yields (77\%) (ESI Fig. S3a-f†). Aiming at a reduction of the necessary synthetic effort, the aromatic hydroxamic acid ("benzyl $\mathrm{HA}-\mathrm{OH}$ ", 2a) was also prepared from the commercially available ester precursor (ESI Fig. S7a-e $\dagger$ ). Additionally lactones were explored for the preparation of aliphatic derivatives (4a, see ESI Scheme $\mathrm{S} 1 \uparrow$ for further details), since naturally occurring hydroxamic acid-based siderophores are typically aliphatic structures. ${ }^{10}$ The preparation of hydroxamic acids from lactones is known in literature. ${ }^{30}$ The conversion of caprolactone to N,6-dihydroxyhexanamide (4a) (ESI Fig. S9a-f $\dagger$ ) and valerolactone to $N, 5$-dihydroxypentanamide (Scheme $\mathrm{S} 1 \dagger$ compound 5) proceeded smoothly in moderate yields, but all attempts to convert butyrolactone to $N, 4$-dihydroxybutanamide led to complex mixtures requiring excessive purification efforts. In summary, the aromatic hydroxamic acids $\mathbf{1} \mathbf{b}$ and $\mathbf{3} \mathbf{a}$, as well the aliphatic hydroxamic acids $\mathbf{4 a}$ and $\mathbf{5}$ fulfilled the necessary requirements for facile and large-scale synthesis and were subsequently used for conversion to 1,4,2-dioxazoles.

Optimization of the protection and deprotection reaction. The anionic ring opening polymerization of epoxides employs both strong nucleophilic as well as harsh basic conditions. Therefore, any carbonyl compound and protic groups have to be protected. The 1,4,2-dioxazole group was chosen as a suitable protection group, as it can be expected to withstand the harsh conditions of AROP. Besides its inert character against strongly basic conditions, the 1,4,2-dioxazole group has been reported to be stable against other nucleophiles, such as EtMgBr, oxidation with $\mathrm{KMnO}_{4}$ or reduction by $\mathrm{NaBH}_{4}$. In this context, the four hydroxamic acid derivatives $\mathbf{1 b}, \mathbf{2 a}, \mathbf{3 a}$ and $\mathbf{4 a}$ were converted to the corresponding 1,4,2-dioxazoles (Scheme 2). This 1,4,2dioxazole group can be viewed as the acetonide derivative of 
a tautomeric form of $\mathbf{1 b}$ and is therefore designated "hydroxamic acid acetonide" (HAA). As reported in a different context by Couturier et al. ${ }^{31}$ and Geffken and Froböse, ${ }^{32}$ the transketalization of hydroxamic acids is unfortunately not straightforward. Varying amounts of side products, depending on the substituent adjacent to the hydroxamic acid, is formed during the reaction. In this side reaction $O$-acyl acetone oxime (see Scheme 3I for an exemplary structure) is formed, which readily reacts with nucleophiles such as alcohols to form esters. The amount of side product is significantly higher for aliphatic hydroxamic acids ( $8: 1$ dioxazole : side product) compared to aromatic derivatives (25-30: 1 dioxazole : side product) ${ }^{31}$ For evaluation purposes, all three aromatic hydroxamic acids (1) 2a and 3a) were converted to the corresponding 1,4,2-dioxazoles. As expected, the side reaction occurred in only negligible amounts (ESI Fig. S4a-f, S6a-e and S8a-e $\dagger$ ).

Surprisingly, the reaction starting from the aliphatic hydroxamic acid $\mathbf{4 a}$ proceeded to form mainly caprolactone by intramolecular ring closure of the $O$-acyl acetone oxime side product (Scheme 2, see Fig. S10 $†$ for ${ }^{1} \mathrm{H}$ NMR of 1,4,2-dioxazole, after purification still some caprolactone is left due to troublesome separation). Hence, intramolecular attack of the hydroxyl group appears to enhance the side reaction, limiting the overall yield $(<23 \%)$ of the desired aliphatic 1,4,2-dioxazole derivative. Attempts to prepare 4-(5,5-dimethyl-1,4,2-dioxazol-3-yl)butan-1ol from valerolactone via the hydroxamic acid 5 completely failed and led to this side reaction exclusively (Scheme 4). Considering the synthetic effort and low yields, the aliphatic (4b) as well aromatic (2b) protected hydroxamic acid were not further used for any polymerization. These findings suggest that a rigid spacer like the aromatic ring is beneficial for the preparation of hydroxyl functional 1,4,2-dioxazoles via transketalization.

Suitable hydroxamic acid initiators for the oxyanionic polymerization have to be both aprotic and base-stable and must possess one hydroxyl group that can be used to form the corresponding alkoxide-initiator salt for the anionic ring opening polymerization. Both aromatic protected hydroxamic acids (1c "HAA-OH”, 3b “benzyl HAA-OH”) fulfil these requirements for AROP and have been successfully used for the preparation of functional polyethers (see below). For the different polymer molecular weight series, 1c was selected due to methyl paraben being a cheap and widely commercially available starting material. We emphasize that this synthetic route employs only inexpensive and commercially available chemicals, permitting

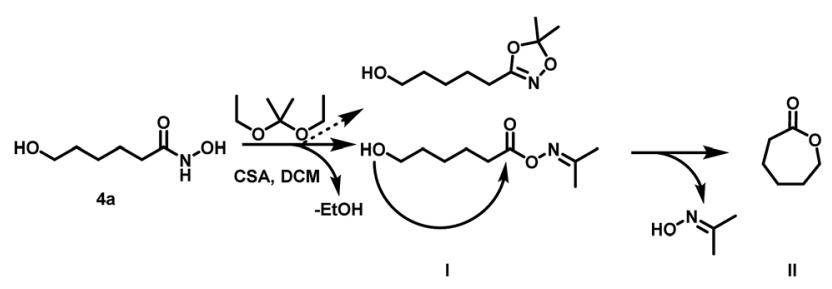

Scheme 3 Side reaction during transketalization of 4 a leading to caprolactone (II) via formation of $\mathrm{O}$-acyl acetone oxime (I) and subsequent intramolecular ring closure.

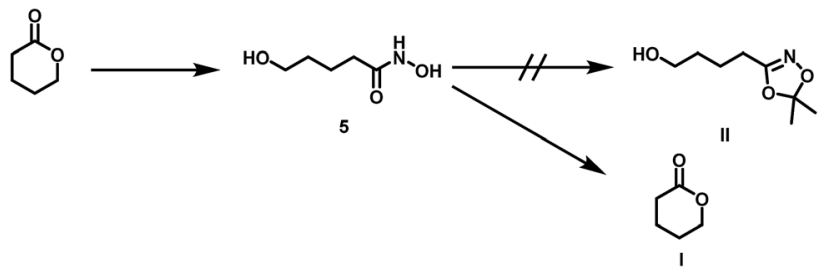

Scheme 4 Side reaction during transketalization of 5 leading to valerolactone (I) via formation of $O$-acyl acetone oxime, subsequent intramolecular ring closure.

scale-up to $20 \mathrm{~g}$ with $64 \%$ overall yield. We have to emphasize that although the aliphatic initiator $\mathbf{4 b}$ was not used in this work for further polymerization, aliphatic hydroxamic acids can be installed in polyethers via this approach. Additionally, to further demonstrate the wide applicability of this approach HAA-OH (1b) was used as a starting material for the preparation of an 1,4,2-dioxazol bearing glycidyl ether (1d) and a methacrylate derivative (1e). The hydroxamic acid acetonide glycidyl ether (HAAGE) was synthesized in high yields (81\%) from $\mathbf{1 b}$ via phase transfer catalysis in a one-step reaction (See ESI Fig. S11† for NMR analysis). Methacrylate hydroxamic acid acetonide (MAHAA) (1e) was obtained via Steglich esterification of $\mathbf{1 b}$ with methacrylic acid (See ESI Fig. S12 $\uparrow$ for NMR analysis). Polymers based on both monomers are currently in progress and will be reported in a forthcoming work. To sum up, hydroxyl-functional 1,4,2-dioxazoles represent the key structure for the preparation of monomers and polymers.

\section{B. Polymer synthesis: hydroxamic acid functional polyethers}

$\alpha$-Functional polyethers were prepared from the two selected functional initiators 1c, $\mathbf{3 b}$ to introduce one terminal hydroxamic acid (HA) moiety. Although this limits the binding capacity for metal ions, the use of a single complexing moiety inherently prevents crosslinking via metal chelation, thus providing watersoluble complexes in case of PEG. This requirement is essential to avoid aggregation of coated nanoparticles or gelation.

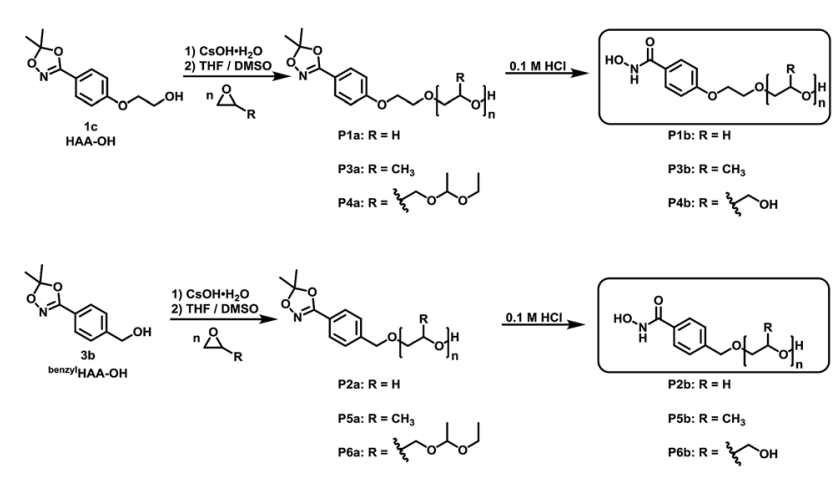

Scheme 5 Synthesis of HAA based polyethers (HAA-PEG, HAA-PPO, HAA-PEEGE) and subsequent cleavage of the protecting group to release the free hydroxamic acid functional polyethers (HA-PEG, HAPPO, HA-linPG). 
HAA-poly(ethylene glycol)s (HAA-PEGs) P1a, P2a with molecular weights in the range of 1000 to $8500 \mathrm{~g} \mathrm{~mol}^{-1}$ were prepared via AROP of ethylene oxide (Scheme 5, Table 1) in THF/ DMSO. The preparation of polyethylene glycol based polymers was chosen as PEG represents the gold standard polymer for biomedical application. Also polymers based on propylene oxide (PO) P3a, P5a and ethoxy ethyl glycidyl ether (EEGE) P4a, P6a have been prepared to broaden the scope of materials and to demonstrate general application of 1c. Polypropylene oxide (PPO) was chosen as a hydrophobic polyether counterpart to PEG. PPO exhibits a lower critical solution temperature (LCST), enabling temperature dependent aqueous solubility below $20^{\circ} \mathrm{C}$ (for $\mathrm{PPO}_{50}$ ) ${ }^{26,33}$ One downside of linear polyethers is their limited number of functional groups. In the case of functional initiated polyethers like in this work, only the terminal $\mathrm{OH}$ group can be addressed for further functionalization of the polymers. To overcome this issue, poly(ethoxy ethyl glycidyl ether) (PEEGE) polymers were prepared. EEGE is an acetalprotected glycidol monomer. These hydrophobic PEEGE polymers can easily be converted (by acidic treatment) to hydrophilic linear polyglycerol (linPG), which exhibits one hydroxyl group per repeating unit, enabling access to multi-functional polyethers. $^{33}$

In all cases full conversion was achieved within $24 \mathrm{~h}$ reaction time. All HAA-PEG, HAA-PPO and HAA-PEEGE polymers exhibit monomodal molecular weight distributions with narrow dispersities below 1.20 (Fig. 1, Table 1, ESI Fig. S1 $\dagger$ ). The degree of polymerization was kept low (10-20) for both the PPO and PEEGE polymers to limit this side reaction. Higher degrees of polymerization are possible, based on these proof-of-principle studies and further optimization. Purification of the polymers was performed via partitioning between water and DCM to obtain the salt-free, pure polymers in good yields (73-94\%).

For all polymerizations conducted good agreement of target molecular weights with molecular weights determined via NMR end group analysis can be confirmed. Slight differences are accounted to the normalization of the integrals to the initiator, leading to uncertainties in the determination of approx. $\pm 250 \mathrm{~g}$

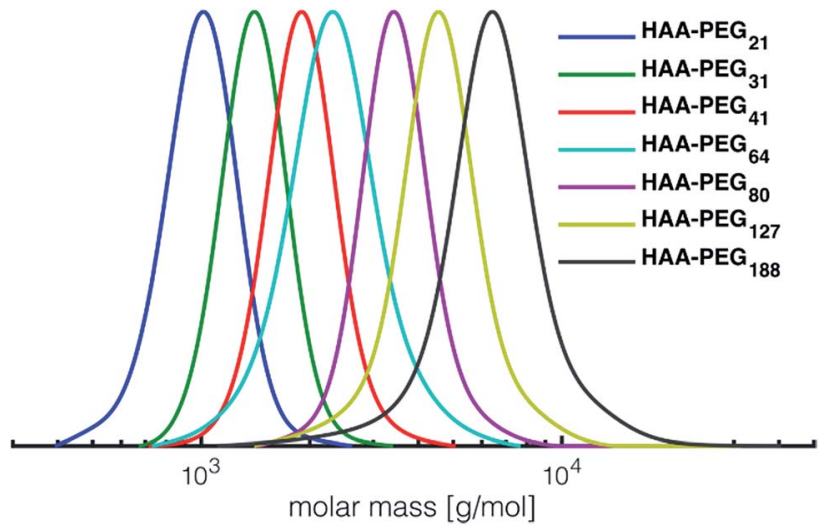

Fig. 1 SEC traces of the prepared HAA-PEGs (DMF, PEG-calibration). HA-PEGs after deprotection strongly interact with SEC column material and hence cannot be analyzed via SEC. See Fig. S1 $\uparrow$ for SEC traces of PPO and PEEGE as well benzyl $\mathrm{HAA}-\mathrm{OH}$ initiated polymers.

mol $^{-1}$. The discrepancy between SEC and NMR molecular weight can be explained by the PEG standards used for calibration. Similar underestimation of molecular weights via SEC have been reported for both PPO as well PEEGE polymers. ${ }^{33}$ In case of PEEGE slight broadening of the molecular weight distribution can be detected. This is attributed to the high polymerization temperature of EEGE $\left(80^{\circ} \mathrm{C}\right)$, increasing known side reactions such as proton abstraction and elimination, leading to overall broadening of the molecular weight distribution. $^{34}$

${ }^{1} \mathrm{H}$ NMR analysis confirms (ESI Fig. S13-S18 $\dagger$ ) the successful initiation of the polymers from either HAA-OH or ${ }^{\text {benzyl }} \mathrm{HAA}-\mathrm{OH}$ respectively. This can further be verified by the excellent overlap of UV and RI signal in SEC measurements (not shown). The thermo-responsive behaviour of $\mathrm{HAA}-\mathrm{PPO}_{21}$ was investigated in deionized water. As expected, a cloud point at $12.9{ }^{\circ} \mathrm{C}$ was observable (ESI Fig. S2 $\dagger$ ), at which the aqueous solution turned turbid and HAA-PPO ${ }_{21}$ precipitated. In summary, both hydroxylfunctional protected hydroxamic acids have been proven to be

Table 1 Overview of the prepared protected hydroxamic acid functional polyethers

\begin{tabular}{|c|c|c|c|c|}
\hline Polymer & $M_{\mathrm{n}}$ target $\left[\mathrm{g} \mathrm{mol}^{-1}\right]$ & $M_{\mathrm{n}}(\mathrm{NMR})^{a}\left[\mathrm{~g} \mathrm{~mol}^{-1}\right]$ & $M_{\mathrm{n}}(\mathrm{SEC})^{b}\left[\mathrm{~g} \mathrm{~mol}^{-1}\right]$ & $D^{b}$ \\
\hline HAA-PEG 21 & 990 & 1160 & 960 & 1.06 \\
\hline HAA-PEG 31 & 1470 & 1600 & 1370 & 1.05 \\
\hline HAA-PEG 64 & 3010 & 3050 & 2210 & 1.11 \\
\hline HAA-PEG 80 & 3800 & 3760 & 3380 & 1.06 \\
\hline HAA-PEG $_{127}$ & 6180 & 5830 & 4360 & 1.09 \\
\hline benzyl HAA-PEG & 4220 & 3510 & 1810 & 1.07 \\
\hline HAA-PPO ${ }_{21}$ & 1400 & 1460 & 1360 & 1.06 \\
\hline benzyl HAA-PPO ${ }_{21}$ & 1370 & 1430 & 1310 & 1.07 \\
\hline HAA-PEEGE $_{7}$ & 1700 & 1410 & 860 & 1.22 \\
\hline HAA-PEEGE $_{26}$ & 4470 & 4180 & 1790 & 1.14 \\
\hline${ }^{\text {benzyl }}$ HAA-PEEGE 6 & 1670 & 1080 & 880 & 1.20 \\
\hline
\end{tabular}

${ }^{a}$ Determined via end group analysis in NMR. ${ }^{b}$ DMF SEC, PEG standard. 
a viable initiator for the polymerization of various epoxide monomers, leading to water-soluble hydrophilic PEG, thermoresponsive PPO or multi-functional PEEGE polymers bearing a terminal hydroxamic acid unit.

Cleavage of the protecting group and release of the free hydroxamic acid moiety. In an optimized procedure, cleavage of the protecting group was achieved by simple treatment of the HAA-PEGs with 0.1 molar HCl. These acidic conditions lead to degradation of the dioxazole structure, thus liberating the free hydroxamic functional PEG (HA-PEG, P1b) in quantitative yields. Compared to the reported deprotection scheme of Couturier et al. this greatly reduces the necessary effort by omitting the usage of ion-exchange resins. ${ }^{31}$ Successful cleavage of the acetal protecting group can both be confirmed via ${ }^{1} \mathrm{H}$ NMR (Fig. 2, ESI Fig. S13b $\dagger$ ) and mass spectra (Fig. 3). No signal of the dioxazole methyl group was detected in the product. Furthermore, both signals of the labile $\mathrm{NH}$ and $\mathrm{OH}$-protons are observed at 11.06 and $8.90 \mathrm{ppm}\left({ }^{1} \mathrm{H}\right.$ NMR) in DMSO- $d_{6}$. The polyether backbone remained unaltered.

ESI mass spectra reveal only the desired HAA-PEG and HAPEG species, respectively. Comparing both polymers, a distinct shift of $40 \mathrm{~g} \mathrm{~mol}^{-1}$, corresponding to cleavage of the protecting group, can be seen. Each spectrum shows only the distribution of the polymers with $44.05 \mathrm{~g} \mathrm{~mol}^{-1}$ per repeating unit. No sub-distribution can be detected (see ESI Fig. S19 and $\mathrm{S} 20 \dagger$ for full spectra).

Both protecting groups employed in the synthesis of HAAPEEGE (P6a) are acetals. Hence, the cleavage of both protecting groups can be achieved simultaneously via acidic treatment. Due to the hydrophobicity of PEEGE the cleavage is very slow in aqueous media. For improved reaction kinetics, the cleavage was performed in isopropanol solution with DOWEX 10WX8 acidic ion exchange resin, leading to HA-linPG (P6b) (Scheme 6).

Full cleavage of the protecting groups is confirmed via ${ }^{1} \mathrm{H}$ NMR spectroscopy (Fig. 4). After treatment with DOWEX10WX8 in isopropanol all acetal signals of PEEGE (Fig. 4 yellow) as well the methyl signals of the 1,4,2-dioxazole group at 1.6 ppm (Fig. 4 green) have vanished. The free hydroxamic acid can be confirmed via the NH-signal appearing at 11 ppm (Fig. 4 blue, top). In conclusion, the 1,4,2-dioxazole group can be
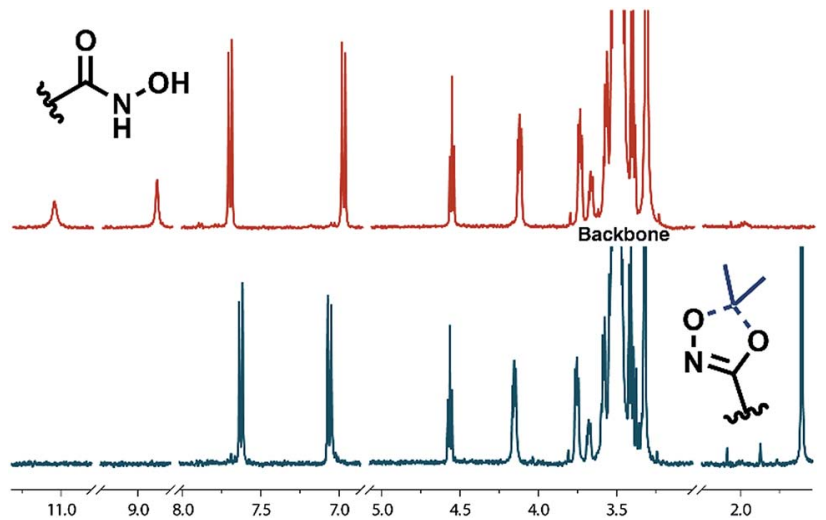

Fig. $2{ }^{1} \mathrm{H}$ NMR analysis of HAA-PEG (bottom) and HA-PEG (top) after cleavage of the protecting group.

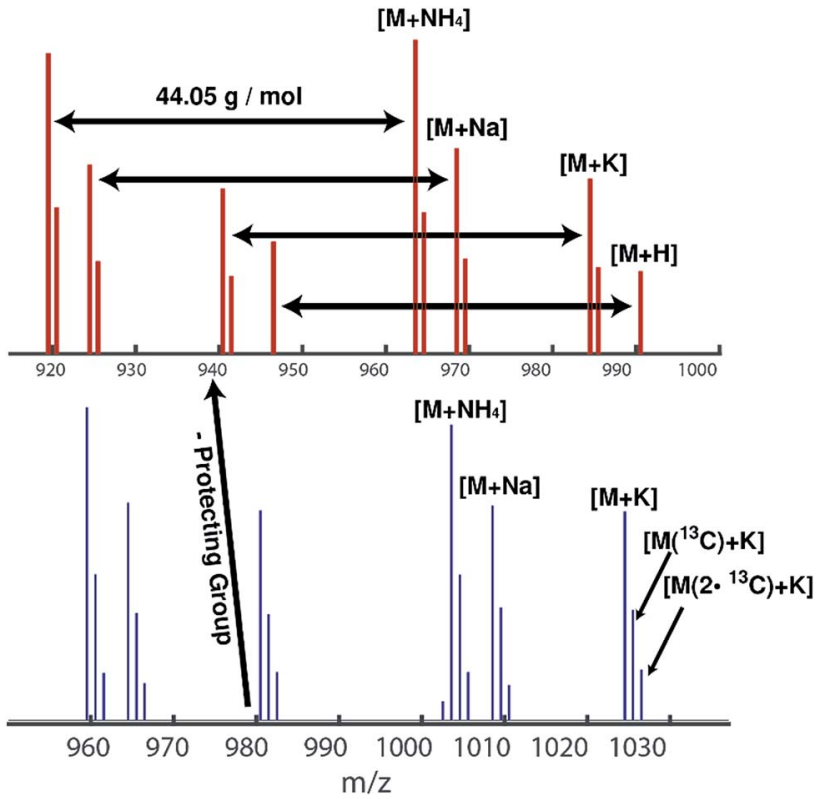

Fig. 3 ESI-mass spectra of HAA-PEG (bottom) and HA-PEG $_{31}$ (top).

simultaneously cleaved with other protecting groups reacting under the same acidic conditions, like acetals without interference leading to multi-functional linPG bearing one hydroxamic acid (Scheme 6). Considering the high stability of the 1,4,2-dioxazole group under basic conditions, orthogonal protecting group chemistry should also be possible for selective release of the functional moieties.

Chelation characterization and demonstration of the applicability of hydroxamic acid functional PEG

Chelation properties. Fundamental chelation properties of the HA-PEGs were investigated, relying on UV-Vis spectroscopy of the highly colored iron(III) complexes. As already reported by Winston et $a .^{16}$, at low iron(III) concentration the tris(hydroxamato)iron(III) complex is favored. When increasing the iron(III) to HA-PEG ([Fe]/[HA-PEG]) ratio the tris-complex is consecutively cleaved to form bis- and finally mono(hydroxamato) iron(III) complexes (Scheme 7). Simultaneously, the color changes from the red tris-complex $\left(\lambda_{\max }=500 \mathrm{~nm}\right)$ to the purple mono-complex $\left(\lambda_{\max }=550 \mathrm{~nm}\right)$ (Fig. 5, ESI Fig. S21). This distinct shift cannot be detected in case of chelating trishydroxamic acids such as deferoxamine due to their highly favored formation of tris-complexes. ${ }^{\mathbf{1 6}}$

This behavior can also be verified by a steep increase in absorbance in the course of iron(III) chloride addition, until

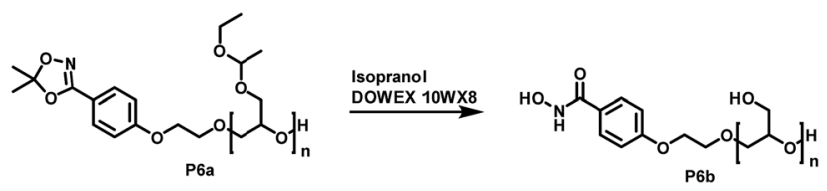

Scheme 6 Reaction scheme for cleavage of the protecting group in HAA-PEEGE releasing both the hydroxyl groups as well as the hydroxamic acid moiety. 


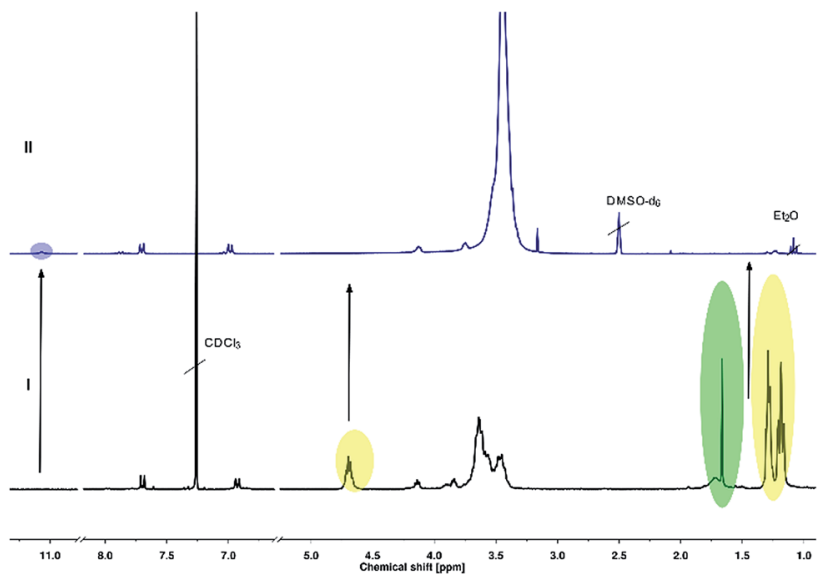

Fig. 4 Stacked ${ }^{1} \mathrm{H}$ NMR spectra of $\mathrm{HAA}-\mathrm{PEEGE}_{7}$ (I) before cleavage of the protecting groups and (II, top) $\mathrm{HA}^{-}$lin $\mathrm{PG}_{7}$ as the reaction product.

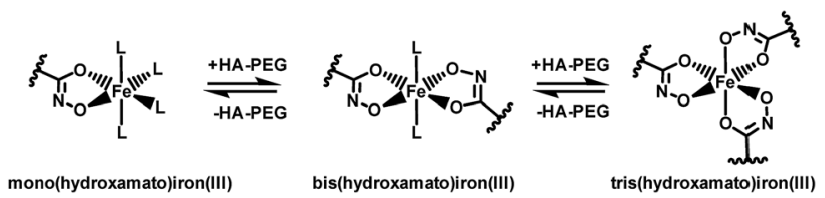

Scheme 7 Equilibria of the formation of mono-, bis-, or tris(PEGhydroxamato)iron(III) complexes.

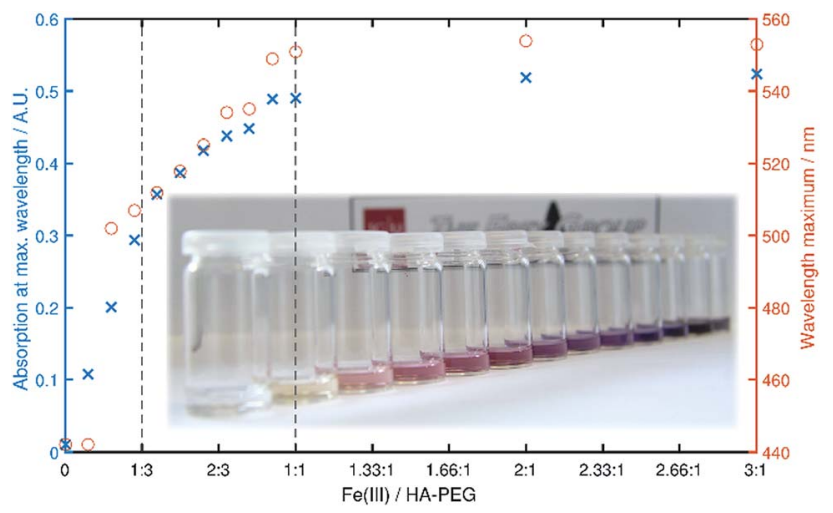

Fig. 5 Maximum absorbance (blue) and $\lambda_{\max }$ (red) in dependency of the $[\mathrm{Fe}] /\left[\mathrm{HA}-\mathrm{PEG}_{188}\right]$ ratio. The vertical lines denote a ratio of $1: 3$ (tris complex) and $1: 1$ (mono complex) respectively.

a ratio of $1: 3([\mathrm{Fe}] /[\mathrm{HA}-\mathrm{PEG}])$ is achieved. With further addition of iron(III) the absorbance increases until equimolarity is obtained. At this ratio all hydroxamic acid moieties are saturated as mono-complexes, and thus no increase in absorbance can be induced by further addition of iron(III). This behavior suggests that there is no influence of the polymer chain on the chelation behavior of the hydroxamic acid end group connected to the polyether backbone. Hence, the chelation properties of HA-PEGs are comparable to low molecular weight hydroxamic acids and are not altered due to the conjugation with PEG.
Nanoparticle and surface modification. Besides binding of low molecular iron, the coating of macroscopic surfaces or metal oxide nanoparticles is another prominent application of polymeric chelators. ${ }^{1}$ As a proof of principle for the coating of surfaces with HA-PEGs, solubilization of iron oxide nanoparticles $\left(\mathrm{FeO}_{x}-\mathrm{NP}\right)$ in water as well as enhancement of the hydrophilicity of different metal surfaces were demonstrated (ESI Fig. S22 and S23†). In all cases, the hydrophilicity of the surfaces increased due to coating with HA-PEGs. By coating $\mathrm{FeO}_{x}$-NP with HA-PEGs with a molecular weight of 1000,3800 and $8500 \mathrm{~g} \mathrm{~mol}^{-1}$ the NP diameter was systematically increased from $20 \mathrm{~nm}$ for the oleate-coated NP up to $50 \mathrm{~nm}$ in case of HAPEG with a molecular weight of $8500 \mathrm{~g} \mathrm{~mol}^{-1}$. Control experiments with non-functionalized PEG resulted only in minor changes in size within the error range of the uncoated NP distribution (Fig. 6, see Table S1†).

After coating, the initially water-insoluble NPs were freely soluble in water or methanol (ESI Fig. S21†). TEM images prepared from water show the coated, non-agglomerated NPs (Fig. 7). As expected, no differences in size or distribution in comparison to the NP prior to coating can be detected.

Cell toxicity and proliferation assays. First, biocompatibility tests were performed using primary human blood cells to explore applicability of the polymers for the transport of $\mathrm{Fe}(\mathrm{III})$ or other metal ions in medicine. In all cases HA-PEG as well as their protected counterpart HAA-PEG showed no significant impact on the metabolic cell activity within the range of tested concentrations, thus low to no toxicity can be expected (ESI Fig. S24 and S26†). To further investigate the shielding effect of the PEG chain, T-Cell proliferation studies were performed.

Commercially available hydroxamic acid-based drugs like deferoxamine mesylate (Desferal, Novartis) are known to strongly inhibit T-cell proliferation. ${ }^{35}$ In contrast HAA-PEG, as well as HA-PEG with a MW of $8500 \mathrm{~g} \mathrm{~mol}^{-1}$ did not significantly influence the proliferation of T-cells, while the low molecular weight HA 1b showed dose-dependent inhibition of the proliferation (Fig. 8, ESI Fig. S25†).

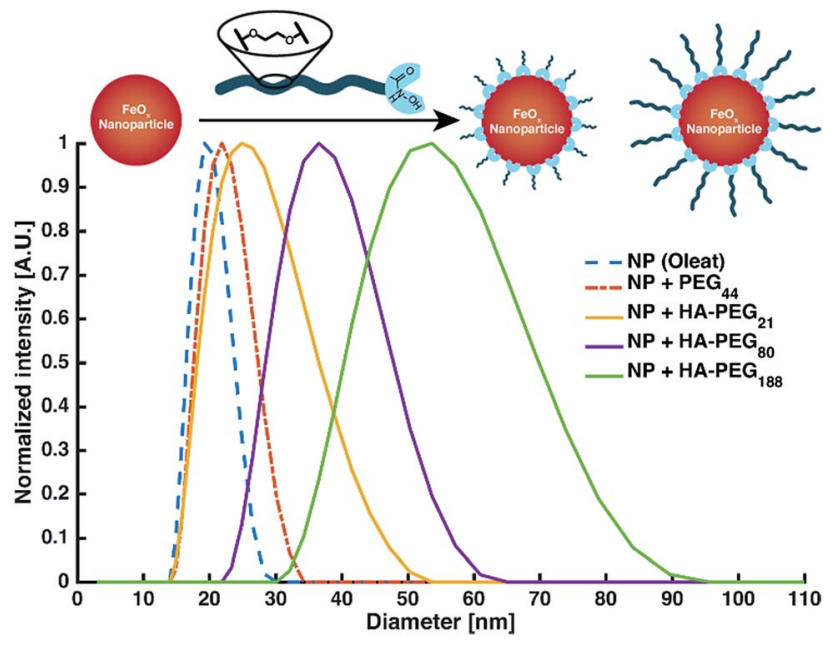

Fig. 6 Intensity distribution of the $\mathrm{FeO}_{x}$ nanoparticles by DLS. 

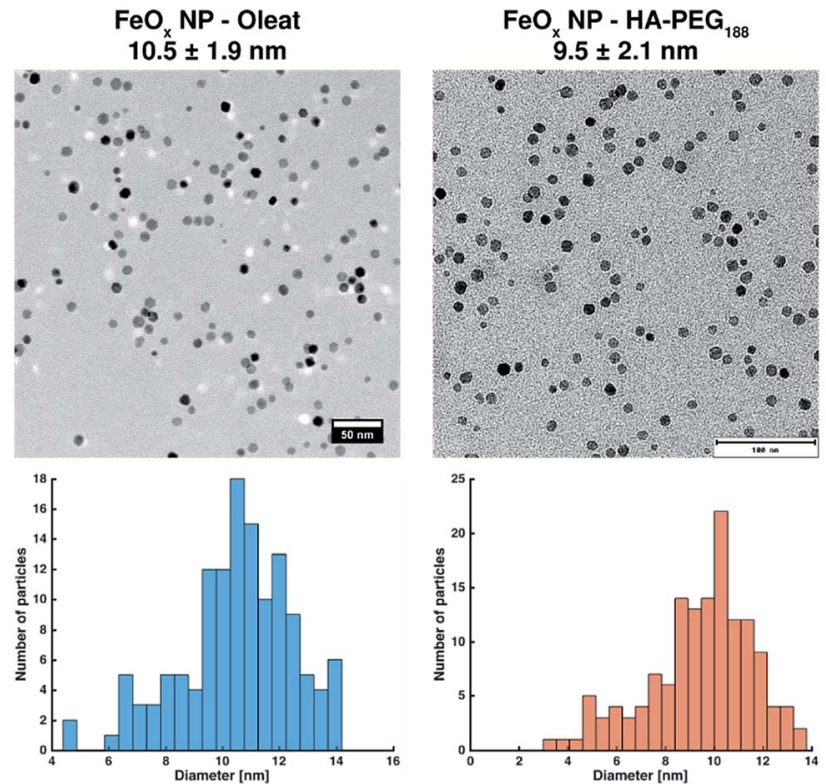

Fig. 7 TEM image of non-modified (oleate coated) $\mathrm{FeO}_{x}$ nanoparticles (left, blue histogram, prepared from hexane) and $\mathrm{FeO}_{x}$ nanoparticles after coating with $\mathrm{HA}-\mathrm{PEG}_{188}$ (right, red histogram, obtained from aqueous solution).

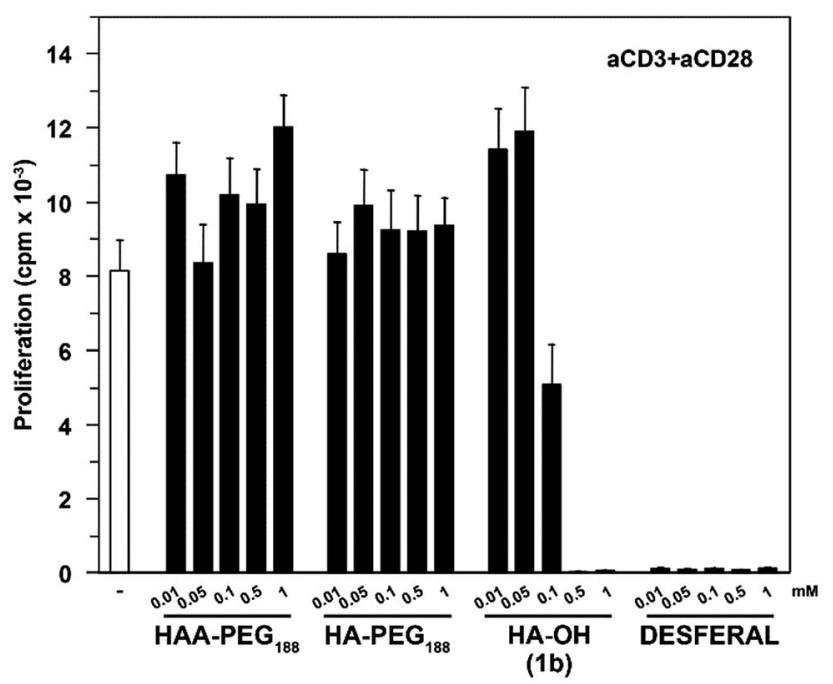

Fig. 8 T-Cell proliferation assay. Human PBMC (4 donors) were stimulated with $\mathrm{aCD} 3$ and $\mathrm{aCD} 28$ antibodies to induce T-cell proliferation in the presence of different test compounds.

\section{Conclusions}

1,4,2-Dioxazoles with an adjacent hydroxyl group have been demonstrated to represent key structures for the direct introduction of hydroxamic acids into polymers. These structures permit to install hydroxamic acids at synthetic polymers in a well-defined manner at the $\alpha$-position. A general synthetic scheme was developed that gives access to a large variety of novel functional key building blocks that can be universally used to obtain hydroxamic acid-based monomers and polymers, for instance as protected HAfunctional initiators or for the synthesis of a variety of novel HA-based monomers, exemplified by epoxides and methacrylates in this work.

Relying on these novel synthons, hydroxamic acid functional polyethers based on ethylene oxide, propylene oxide and ethoxy ethyl glycidyl ether, respectively, were prepared to show the general applicability of this approach, even under the harsh conditions of the AROP. After mild acidic treatment of the resulting polyethers, the free hydroxamic acid can be recovered. Consequently, hydroxyl-functional 1,4,2-dioxazoles are broadly applicable for the initiation of AROP or for preparation of HAbased monomers by modification of the hydroxyl group with polymerizable structures.

The HA-initiated polyethers were studied both with respect to their future use in materials science and for medical purposes, for instance in the treatment of diseases related to the iron metabolism. No measureable difference in terms of chelation properties of the hydroxamic acid functional polyethers was detected, compared to low molecular weight hydroxamic acids, while anti-proliferative effects of low molecular weight hydroxamic acid therapeutics like deferoxamine were highly reduced. The complexation of $\mathrm{Fe}(\mathrm{III})$ ions, the coating of various metal surfaces as well as $\mathrm{FeO}_{x}$ nanoparticles confirm outstanding chelation properties. From these proof-of-principle studies and the basic synthons established in this work, a vast variety of typical applications known for other polymeric chelators, such as catechol-bearing or terpyridine-bearing polymers become viable. The combination of hydroxamic acids with polymers is a promising alternative to catechols with their low oxidative stability. Hydroxamic acid based polyethers offer promise for irondepletion therapies, for medical purposes related to metal ion transport in general as well as in materials science and for surface coating.

Based on the general concept for protected hydroxamic acids introduced in this work, a variety of novel monomers based on acrylates, methacrylates and epoxides has been prepared and polymerized. These structures and their use for both material science and medicine will be reported in due course.

\section{Experimental section}

\section{Materials}

Unless otherwise stated, all reagents were used without further purification. All chemicals and solvents were purchased from Acros, Aldrich, Fisher Scientific, Fluka, Riedel-de-Haën or Roth. Deuterated solvents were purchased from Deutero GmbH. THF was dried via distillation over sodium/benzophenone. DMSO was dried using molecular sieve 4 A. Hydrophobic $\mathrm{FeO}_{x}$ nanoparticles coated with oleic acid were provided by Jan Hilgert (Group of Prof. Tremel, University of Mainz).

\section{Abbreviations}

Ethyl acetate (EA), petrol ether (PE), dichloromethane (DCM), tetrahydrofuran (THF), dimethyl sulfoxide (DMSO), ethylene 
oxide (EO), camphor sulfonic acid (CSA), methanol (MeOH), correlation spectroscopy (COSY), heteronuclear single-quantum correlation spectroscopy (HSQC), heteronuclear multiple-bond correlation spectroscopy (HMBC).

\section{Characterization techniques}

NMR analysis. ${ }^{1} \mathrm{H}$ NMR spectra at $300 \mathrm{MHz}$ and ${ }^{13} \mathrm{C}$ spectra at $75 \mathrm{MHz}$ were recorded on a Bruker Avance III HD $300(5 \mathrm{~mm}$ BBFO-Head with $z$-gradient) at $23{ }^{\circ} \mathrm{C} .{ }^{1} \mathrm{H}$ NMR spectra at 400 $\mathrm{MHz}$ and ${ }^{13} \mathrm{C}$ spectra at $100 \mathrm{MHz}$ were recorded on a Bruker Avance III HD 400 (5 mm BBFO-Smartprobe with $z$-gradient) at $23{ }^{\circ} \mathrm{C}$. The spectra are referenced internally to residual proton signal of the deuterated solvent. In the rare case of no detectable residual proton signal in $2 \mathrm{D}$ measurements, the spectra are referenced to compound signals from 1D spectra. All signals are assigned according to IUPAC nomenclature guidelines. For better clarity, the 2D spectra are annotated using lowercase letters for proton signals and capital letters for carbon signals.

Size exclusion chromatography. SEC chromatography was performed in DMF $\left(1 \mathrm{~mL} \min ^{-1}, 50{ }^{\circ} \mathrm{C}\right)$ containing $1 \mathrm{~g} \mathrm{~L}^{-1}$ lithium bromide as an additive, using an Agilent 1100 series SEC system including a HEMA 300/100/40 A column cascade, a UV $(254 \mathrm{~nm})$ and RI detector. Calibration was carried out using poly(ethylene oxide) (PEO) standards provided by Polymer Standard Service (PSS).

Mass spectrometry. Polymer mass spectra were recorded on an Agilent 6545 QTOF mass spectrometer in electron spray ionization (ESI) mode. Sample concentration was $1 \mathrm{mg} \mathrm{mL}^{-1}$ in methanol. Mass spectra of low molecular weight compounds were recorded using a Finnigan MAT 95 mass spectrometer in field desorption (FD) mode.

Ultraviolet-Visible spectroscopy. UV-Vis spectra were recorded on a JASCO V-630 spectrophotometer in the range of $230 \mathrm{~nm}$ to $800 \mathrm{~nm}$ with $1 \mathrm{~nm}$ data interval. Scan speed was set to $400 \mathrm{~nm} \mathrm{~min}{ }^{-1}$. All samples were prepared in methanol.

Dynamic light scattering. DLS measurements were performed on a Zetasizer Nano ZS (Malvern Instruments) at an angle of $173^{\circ}$ and a wavelength of $633 \mathrm{~nm}$ at $25{ }^{\circ} \mathrm{C}$. Three measurements were performed per sample. All DLS measurements were performed in DCM.

Infrared spectroscopy. FT-IR spectra were recorded using a Nicolet iS10 FT-IR spectrometer (Thermo Fisher Scientific) in the range of 500 to $3500 \mathrm{~cm}^{-1}$.

Lower critical solution temperature measurements. Cloud points were determined in deionized water at a concentration of $2.5 \mathrm{mg} \mathrm{mL} \mathrm{m}^{-1}$ and observed by optical transmittance of a laser beam $(670 \mathrm{~nm})$. The measurement was recorded in a Tepper turbidimeter TP1. Heating rate was $1 \mathrm{~K} \mathrm{~min}^{-1}$. For determination of the LCST the temperature at $50 \%$ of initial transmittance was used.

Contact angle measurements. Contact angle measurements were performed after cleaning the appropriate metal slide in acetone by sonification for $1 \mathrm{~h}$. Then each slide was put into either solution of $\mathrm{PEG}_{44}$ as a reference or $\mathrm{HA}-\mathrm{PEG}_{188}$ (each $10 \mathrm{mg} \mathrm{mL}^{-1}$ in DCM) overnight at room temperature. The slides were removed from the solution, dried under air and rinsed with MilliQ-water to remove non-adhered polymer. The contact angle measurement was performed using the sessile drop method by applying one drop of MilliQ water on the surface and determining the apparent angle between liquid and solid phase. Every measurement was performed five times.

Transmission electron microscopy. TEM images were recorded with a FEI Tecnai 12 microscope equipped with a $\mathrm{LaB}_{6}$ cathode $(120 \mathrm{kV}$ acceleration voltage, nominal magnification: 68 000; nominal underfocus: $0.5-1.5 \mathrm{~mm}$ ). For sample preparation, carbon grids for TEM applications were negatively glow discharged at $25 \mathrm{~mA}$ for $30 \mathrm{~s}$ in an Emitech K100X glow discharge system. A droplet of the sample $(5 \mu \mathrm{l})$ was placed on the grid and incubated for $30 \mathrm{~s}$. The grid was dried with Whatman filter paper no. 4 by side-blotting.

Metabolic activity. Potential cytotoxic effects of the various agents on peripheral blood mononuclear cells (PBMC) were monitored by assaying their metabolic activity. For this, PBMC were isolated from blood donations of healthy volunteers by density gradient centrifugation using Ficoll as recommended by the manufacturer (Sigma-Aldrich, Deisenhofen, Germany). PBMC $\left(10^{7} / \mathrm{mL}\right)$ were seeded into wells of 96 well cluster plates (100 $\mu \mathrm{l}$ per well), and agents were applied to triplicates at the concentrations indicated. Samples left untreated or incubated with DMSO at cytotoxic dose $(10 \%)$ were included as controls. On the next day, MTT substrate was applied as recommended by the manufacturer (Promega, Madison, WI). MTT reagent is reduced by mitochondrial dehydrogenases to a purple formazan product. Absorbance was measured at $570 \mathrm{~nm}$ using a EMax Plus microplate reader (Molecular Devices, San José, CA).

Proliferation assays. To assess effects of the different agents on the proliferative capacity of T cells, PBMC $\left(10^{6} / \mathrm{mL}\right)$ were seeded into wells of 96 well cluster plates (100 $\mu \mathrm{l}$ per well). To induce polyclonal $\mathrm{T}$ cell proliferation, wells were precoated with mouse anti-human CD3 antibody $\left(1 \mu \mathrm{g} \mathrm{mL} \mathrm{m}^{-1}\right.$; clone HIT3a), and mouse anti-human CD28 antibody $\left(1 \mu \mathrm{g} \mathrm{mL}{ }^{-1}\right.$; clone CD28.2) was added to PBMC prior to seeding (both antibodies from Biolegend, San Diego, CA). In parallel settings, T cells were stimulated using phytohemagglutinin (PHA) isolated from Phaseolus vulgaris (Sigma-Aldrich) at a final concentration of $5 \mu \mathrm{g} \mathrm{mL}{ }^{-1}$. PBMC left unstimulated served as internal controls. The different agents were applied to triplicates at the concentrations indicated. $\mathrm{T}$ cell proliferation was assayed as genomic incorporation of ${ }^{3} \mathrm{H}$-thymidine ( $0.5 \mu \mathrm{Ci}$ per well) added on day 3 of culture. On the next day, cells were harvested onto glass fiber filters. Retained radioactivity was detected using a $ß$ counter (1205 Betaplate, LKB Wallac, Turcu, Finnland).

Synthesis procedures of hydroxamic acids and 1,4,2dioxazoles

Synthesis of the hydroxamic acid functional initiator (HAA$\mathrm{OH})$ employed as an initiator for polymerization and HAA monomer derivatives (1a-1e). 


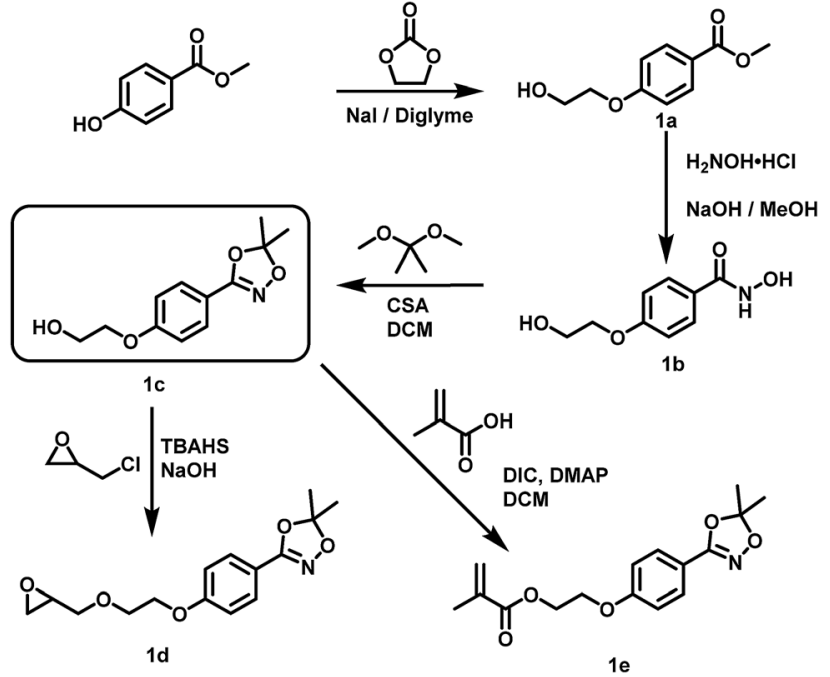

(1a) Methyl 4-(2-hydroxyethoxy)benzoate. (1a) was prepared in a modified procedure described elsewhere. ${ }^{36}$ A $250 \mathrm{~mL}$ flask equipped with a condenser and gas bubbler was charged with $76.07 \mathrm{~g}$ ( $0.500 \mathrm{~mol}, 1.00 \mathrm{eq}$.) methyl 4-hydroxybenzoate, $46.25 \mathrm{~g}$ ( $0.525 \mathrm{~mol}, 1.05$ eq.) ethylene carbonate, $7.50 \mathrm{~g}$ ( $0.050 \mathrm{~mol}, 0.10$ eq.) $\mathrm{NaI}$ and $100 \mathrm{~mL}$ diglyme and heated under vigorous stirring for $16 \mathrm{~h}$ at $140{ }^{\circ} \mathrm{C}$ oil bath temperature. Finally, the temperature was increased to $160{ }^{\circ} \mathrm{C}$ for two hours. The solution was cooled to room temperature and the solvent were removed until dryness in vacuo. The residue was dissolved in $300 \mathrm{~mL}$ EA and washed with $50 \mathrm{~mL}$ water, $50 \mathrm{~mL}$ saturated $\mathrm{NaHCO}_{3}$ and $50 \mathrm{~mL}$ brine and dried using $\mathrm{Na}_{2} \mathrm{SO}_{4}$. After evaporation of the solvent $93.6 \mathrm{~g}(0.477 \mathrm{~mol}, 95 \%)$ of methyl 4-(2-hydroxyethoxy)benzoate were obtained.

${ }^{1} \mathrm{H}$ NMR $\left(300 \mathrm{MHz}, \mathrm{CDCl}_{3}\right) \delta[\mathrm{ppm}]=7.99\left(\mathrm{AA}^{\prime} \mathrm{BB}^{\prime}, 2 \mathrm{H}\right.$, $\left.H \mathrm{C}^{2,6}\right), 6.93\left(\mathrm{AA}^{\prime} \mathrm{BB}^{\prime}, 2 \mathrm{H}, H \mathrm{C}^{3,5}\right), 4.17\left(\mathrm{t}, J=4.1 \mathrm{~Hz}, 2 \mathrm{H}, \mathrm{CH}_{2}-\mathrm{O}-\right.$ $\mathrm{Ar}), 3.99\left(\mathrm{t}, J=4.1 \mathrm{~Hz}, 2 \mathrm{H}, \mathrm{HO}-\mathrm{CH}_{2}-\right), 3.88\left(\mathrm{~s}, 3 \mathrm{H}, \mathrm{CH}_{3}\right)$.

${ }^{13} \mathrm{C} \mathrm{NMR}\left(75 \mathrm{MHz}, \mathrm{CDCl}_{3}\right) \delta[\mathrm{ppm}]=166.92 \mathrm{Ar}-\mathrm{C}=\mathrm{O}, 162.48$ $\mathrm{C}^{4}, 131.78 \mathrm{C}^{2,6}, 123.13 \mathrm{C}^{3,5}, 114.24 \mathrm{C}^{1}, 69.45 \mathrm{Ar}-\mathrm{O}-C, 61.42 \mathrm{HO}-$ C, $52.06 \mathrm{CH} 3$.

(1b) N-hydroxy-4-(2-hydroxyethoxy)benzamide. (1b) was prepared in a modified procedure based on the work of Hauser and Renfrow. ${ }^{37} 42.9 \mathrm{~g}$ (0.62 mol, 2.00 eq.) $\mathrm{H}_{2} \mathrm{NOH} \cdot \mathrm{HCl}$ were dissolved in $240 \mathrm{~mL}$ methanol and neutralized by addition of a solution of $52.1 \mathrm{~g}$ (0.93 mol, 3.00 eq.) KOH in $140 \mathrm{~mL}$ methanol. After cooling in an ice-bath for $5 \mathrm{~min}$ the solution was filtered to remove precipitated $\mathrm{KCl}$. To this solution $60.6 \mathrm{~g}$ (0.31 mol, 1.00 eq.) methyl 4-(2-hydroxyethoxy)benzoate (1a) were added in one step, and the solution was stirred until homogenous. After standing for $24 \mathrm{~h}$ at room temperature, the basic solution was acidified with $2 \mathrm{M} \mathrm{HCl}$ to $\mathrm{pH} 4$ and all solvents were removed until dryness in vacuo. The residue was transferred into a soxhlet apparatus and extracted using THF (1000 $\mathrm{mL})$ overnight. After cooling at $-20{ }^{\circ} \mathrm{C}$ and vacuum filtration $47.5 \mathrm{~g}$ ( $0.24 \mathrm{~mol} 77 \%) \mathrm{N}$-hydroxy-4-(2-hydroxyethoxy) benzamide (1b) were obtained as a colourless solid.

${ }^{1} \mathrm{H}$ NMR $\left(300 \mathrm{MHz}, \mathrm{DMSO}-d_{6}\right) \delta[\mathrm{ppm}]=11.06(\mathrm{~s}, 1 \mathrm{H}, \mathrm{N} H)$, $8.90(\mathrm{~s}, 1 \mathrm{H}, \mathrm{NH}-\mathrm{OH}), 7.71\left(\mathrm{AA}^{\prime} \mathrm{BB}^{\prime}, 2 \mathrm{H}, H^{2,6}\right), 6.98\left(\mathrm{AA}^{\prime} \mathrm{BB}^{\prime}, 2 \mathrm{H}\right.$,
$\left.H \mathrm{C}^{3,5}\right), 4.89\left(\mathrm{t}, J=5.5 \mathrm{~Hz}, 1 \mathrm{H}, H \mathrm{O}-\mathrm{CH}_{2}\right), 4.03(\mathrm{t}, J=4.9 \mathrm{HZ}, 2 \mathrm{H}$, $\mathrm{CH}_{2}-\mathrm{O}-\mathrm{Ar}$ ), 3.72 (dt, $\mathrm{J}=5.5,4.9 \mathrm{~Hz}, 2 \mathrm{H}, \mathrm{HO}-\mathrm{CH}_{2}-$ ).

${ }^{13} \mathrm{C}$ NMR $\left(75 \mathrm{MHz}, \mathrm{DMSO}-d_{6}\right) \delta[\mathrm{ppm}]=164.02 C \equiv \mathrm{O}, 160.95$ $\mathrm{C}^{4}, 128.62 \mathrm{C}^{2,6}, 124.82 \mathrm{C}^{1}, 123.13 \mathrm{C}^{3,5}, 69.70 \mathrm{Ar}-\mathrm{O}-C, 59.48 \mathrm{HO}-$ C.

IR-ATR $\nu\left[\mathrm{cm}^{-1}\right]=3279 \mathrm{~m}, 2947 \mathrm{w}, 2750 \mathrm{~m} \mathrm{br}, 1638 \mathrm{~m}, 1606$ vs. $(\mathrm{C}=\mathrm{O}), 1564 \mathrm{~s}, 1503 \mathrm{~s}, 1445 \mathrm{~m}, 1413 \mathrm{~m}, 1378 \mathrm{~m}, 1335 \mathrm{w}, 1304$ m, 1253 vs. (C-O), 1185 m, 1162 m, 1115 w, 1088 s, 1050 s, 1031 m, 1010 m, 919 m, 894 vs., 847 vs., 817 m.

$R_{\mathrm{f}}(\mathrm{EA}: \mathrm{PE}=2: 1)=0.05$.

Elemental analysis. Found C: 53.68, H: 6.09, N: 6.66 - calculated 54.82, H: 5.62, N: 7.10.

FD-MS $(m / z)=197.2532(100 \%), 198.2448$ (8.1\%).

(1c) 2-(4-(5,5-dimethyl-1,4,2-dioxazol-3-yl)phenoxy)ethan-1-ol. (1c) was prepared in a modified procedure based on the work of Couturier et al. ${ }^{31} 19.72 \mathrm{~g}$ (0.10 mol, 1.00 eq.) $N$-hydroxy-4-(2hydroxyethoxy)benzamide (1b) were suspended in $2000 \mathrm{~mL}$ DCM in a dry $3 \mathrm{~L}$ flask. To this suspension $31.25 \mathrm{~g}(0.30 \mathrm{~mol}$, 3.00 eq.) 2,2-dimethoxypropane and $23.23 \mathrm{~g}$ ( $0.10 \mathrm{~mol}, 1.00 \mathrm{eq}$.) camphor sulfonic acid were added. The suspension was vigorously stirred for $15 \mathrm{~h}$ and then neutralized by addition of $250 \mathrm{~mL} 4 \mathrm{M}$ aqueous $\mathrm{NaOH}$ solution. After stirring over night the organic layer was separated and washed twice with $100 \mathrm{~mL}$ $2 \mathrm{M} \mathrm{NaOH}$, dried using $\mathrm{Na}_{2} \mathrm{SO}_{4}$ and evaporated to dryness in vacuo. The pure product was obtained by column chromatography $\left(\mathrm{SiO}_{2}, \mathrm{EA}: \mathrm{PE}=1: 1\right.$ as eluent). Yield: $20.89 \mathrm{~g}(0.088 \mathrm{~mol}$, $88 \%$ ) as colourless liquid that solidified at $-20{ }^{\circ} \mathrm{C}$.

${ }^{1} \mathrm{H}$ NMR $\left(300 \mathrm{MHz}, \mathrm{DMSO}-d_{6}\right) \delta[\mathrm{ppm}]=7.64\left(\mathrm{AA}^{\prime} \mathrm{BB}^{\prime}, 2 \mathrm{H}\right.$, $\left.H \mathrm{C}^{3,5}\right), 6.94\left(\mathrm{AA}^{\prime} \mathrm{BB}^{\prime}, 2 \mathrm{H}, H \mathrm{C}^{2,6}\right) 4.12(\mathrm{t}, J=5.2 \mathrm{~Hz}, 2 \mathrm{H}, \mathrm{Ar}-\mathrm{O}-$ $\mathrm{CH}_{2}{ }^{-}$), 3.98 (t, $\left.J=5.2 \mathrm{~Hz}, 2 \mathrm{H}, \mathrm{HO}-\mathrm{CH}_{2}-\right), 1.66$ (s, 6H, $\mathrm{CH}_{3}$ ).

${ }^{13} \mathrm{C}$ NMR (75 MHz, DMSO- $\left.d_{6}\right) \delta[\mathrm{ppm}]=161.12 \mathrm{C}^{1}, 158.21$ $\mathrm{C}=\mathrm{N}, 128.58 \mathrm{C}^{3,5}, 116.50 \mathrm{C}^{4}, 115.34 C\left(\mathrm{CH}_{3}\right)_{2}, 114.71 \mathrm{C}^{2,6}, 69.45$ $\mathrm{Ar}-\mathrm{O}-\mathrm{CH}_{2}-, 61.43 \mathrm{HO}-\mathrm{CH}_{2}-, 24.97 \mathrm{CH}_{3}$.

IR-ATR $\nu\left[\mathrm{cm}^{-1}\right]=3396 \mathrm{vw}$ br (OH), $2935 \mathrm{vw}, 1710 \mathrm{vw}, 1606 \mathrm{~m}$ $(\mathrm{C}=\mathrm{N}), 1514 \mathrm{~m}, 1454 \mathrm{w}, 1423 \mathrm{~m}, 1363 \mathrm{~m}, 1306 \mathrm{~m}, 1251$ vs., 1215 s, 1166 s, 1115 m, 1078 s, 1044 m, 1010 m, 978 m, 945 w, $916 \mathrm{~m}, 884 \mathrm{~m}, 836 \mathrm{~s}, 816 \mathrm{~m}, 771 \mathrm{~m}$.

$R_{\mathrm{f}}(\mathrm{EA}: \mathrm{PE}=1: 1)=0.38$.

FD-MS $(m / z)=237.2485$ (100\%), 238.2470 (11.5\%), 239.2456 $(1.2 \%)$.

(1d) 5,5-dimethyl-3-(4-(2-(oxiran-2-ylmethoxy)ethoxy)phenyl)1,4,2-dioxazole. A $250 \mathrm{~mL}$ three-necked flask equipped with a dropping funnel, thermometer and mechanical stirrer was charged with $56 \mathrm{~mL} 50 \%(\mathrm{w} / \mathrm{w})$ aqueous $\mathrm{NaOH}$ solution, $35.0 \mathrm{~mL}$ ( $0.45 \mathrm{~mol}, 5.3 \mathrm{eq}$.) epichlorhydrin and $1.18 \mathrm{~g}$ ( $3.5 \mathrm{mmol}$, 0.04 eq.) tetrabutylammonium hydrogen sulfate (TBAHS). $20.0 \mathrm{~g}$ (84.3 mol, 1.0 eq.) 2-(4-(5,5-dimethyl-1,4,2-dioxazol-3-yl) phenoxy) ethan-1-ol were added within 30 minutes while cooling in an ice bath. After addition, the ice bath was removed and the suspension stirred vigorously overnight. After complete conversion of the alcohol was verified via TLC the reaction was quenched by addition of $100 \mathrm{~mL}$ of an ice-water mixture. The organic phase was separated, and the aqueous phase was extracted three times each with $60 \mathrm{~mL}$ dichloromethane. The combined organic phase was washed with brine until a $\mathrm{pH}$ of 8 was obtained, then dried using $\mathrm{Na}_{2} \mathrm{SO}_{4}$, filtered and all solvents 
were removed in vacuo. After column chromatography $\left(\mathrm{SiO}_{2}\right.$, eluent: PE : EA = 4 : 1) 20.0 g (68.2 mmol, 81\%) 5,5-dimethyl-3(4-(2-(oxiran-2-ylmethoxy)ethoxy)phenyl)-1,4,2-dioxazole were obtained as a colourless liquid.

${ }^{1} \mathrm{H}$ NMR (400 MHz, DMSO- $\left.d_{6}\right) \delta=7.68-7.59\left(\mathrm{AA}^{\prime} \mathrm{BB}^{\prime}, 2 \mathrm{H}\right.$, $\left.H \mathrm{C}^{3,5}\right), 7.11-7.02\left(\mathrm{AA}^{\prime} \mathrm{BB}^{\prime}, 2 \mathrm{H}, H^{2,6}\right), 4.21-4.14$ (m, 2H, Ar-O$\mathrm{CH}_{2}-\mathrm{CH}_{2}-$ ), 3.85-3.72 (m, 3H, Ar-O- $\mathrm{CH}_{2}-\mathrm{CH}_{2}$, epoxide- $\mathrm{CH}_{2}-\mathrm{O}$ ), 3.35-3.27 (m, 1H, epoxide- $\mathrm{CH}_{2}-\mathrm{O}$ ), 3.15-3.09 (m, CH), 2.73 (dd, $J$ $=5.1,4.2 \mathrm{~Hz}, 1 \mathrm{H}, \mathrm{CH}_{2}$ in epoxide), $2.56(\mathrm{dd}, J=5.1,2.7 \mathrm{~Hz}, 1 \mathrm{H}$, $\mathrm{CH}_{2}$ in epoxide), 1.61 (s, 6H, acetonide $\left.\mathrm{CH}_{3}\right)$.

(1e) 2-(4-(5,5-dimethyl-1,4,2-dioxazol-3-yl)phenoxy)ethyl methacrylate. In a $50 \mathrm{~mL}$ Schlenk flask $6.06 \mathrm{~g}$ (0.026 mol, $1.10 \mathrm{eq}$.) 2(4-(5,5-dimethyl-1,4,2-dioxazol-3-yl)phenoxy)ethan-1-ol, $2.00 \mathrm{~g}$ (0.023 mol, 1.00 eq.) methacrylic acid and $0.23 \mathrm{~g}$ (1.9 mmol, 0.08 eq.) 4-dimethylaminopyridine (DMAP) were dissolved in $15 \mathrm{~mL}$ dichloromethane. Under ice cooling it was added $3.23 \mathrm{~g}$ (0.026 mol, 1.10 eq.) $N, N^{\prime}$-diisopropylcarbodiimide (DIC) within 5 minutes. After stirring for 15 minutes under ice cooling, the mixture was stirred for $5 \mathrm{~h}$ at $\mathrm{rt}$. The mixture was filtered through a frit, and the filtrate was washed twice with $100 \mathrm{~mL}$ of a saturated sodium hydrogen carbonate solution. The organic phase was dried over $\mathrm{MgSO}_{4}$ and the solvent was removed under reduced pressure. The solid was purified by column chromatography in a solvent mixture of PE : EA $(6: 1)$. Methacrylate hydroxamic acid acetonide (MAHAA, 1e) was obtained in yields of $5.35 \mathrm{~g}$ (0.018 mol, 76\%).

${ }^{1} \mathrm{H}$ NMR $\left(300 \mathrm{MHz}, \mathrm{CDCl}_{3}\right): \delta[\mathrm{ppm}]=7.73\left(\mathrm{AA}^{\prime} \mathrm{BB}^{\prime}, 2 \mathrm{H}\right.$, $\left.H \mathrm{C}^{3,5}\right), 6.93\left(\mathrm{AA}^{\prime} \mathrm{BB}^{\prime}, 2 \mathrm{H}, H \mathrm{C}^{2,6}\right), 6.15(s, 1 \mathrm{H}, H \mathrm{C}=\mathrm{C}), 5.60(s, 1 \mathrm{H}$, $\mathrm{HC}=\mathrm{C}), 4.51\left(m, 2 \mathrm{H}, \mathrm{MA}-\mathrm{O}-\mathrm{CH}_{2}-\right), 4.26\left(m, 2 \mathrm{H}, \mathrm{Ar}-\mathrm{O}-\mathrm{CH}_{2}\right)$, $1.96\left(s, 3 \mathrm{H}, \mathrm{CH}_{3}-\mathrm{C}=\mathrm{C}\right), 1.67\left(s, 6 \mathrm{H}\right.$, acetonide $\left.\mathrm{CH}_{3}\right)$.

Synthesis of phenolic hydroxamic acid functional initiator not employed for polymerization $(2 \mathrm{a}-2 \mathrm{~b})$.
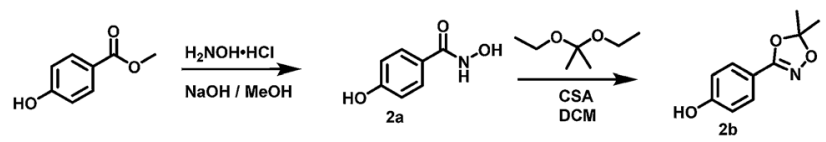

(2a) N,4-dihydroxybenzamide. (2a) was prepared in a modified procedure based on the work of Jeanrenaud et al. ${ }^{38}$ A $250 \mathrm{~mL}$ round bottom flask was charged with $3.80 \mathrm{~g}$ ( $25 \mathrm{mmol}, 1 \mathrm{eq}$.) methyl paraben and $3.47 \mathrm{~g}(50 \mathrm{mmol}, 2$ eq. $) \mathrm{H}_{2} \mathrm{NOH} \cdot \mathrm{HCl}$ in $87.5 \mathrm{~mL}$ water. To this suspension $3.5 \mathrm{~g}$ ( $88 \mathrm{mmol}, 3.5 \mathrm{eq}$.) $\mathrm{NaOH}$ as a $2 \mathrm{M}$ solution was added. After 4 hours of stirring at room temperature the solution was acidified using $110 \mathrm{~mL} 1 \mathrm{M}$ $\mathrm{HCl}$ and cooled overnight at $4{ }^{\circ} \mathrm{C}$. Unreacted reagents were filtered off and the residue reduced in vacuo to few $\mathrm{mL}$ residual volume. The residual aqueous phase was extracted four times with $50 \mathrm{~mL}$ EA each. The combined organic phase was dried using $\mathrm{Na}_{2} \mathrm{SO}_{4}$ and freed from any solvents in vacuo. The crude product was purified using column chromatography $\left(\mathrm{SiO}_{2}\right.$, $\mathrm{PE}: \mathrm{EA}=1: 1$ as starting eluent, increasing elution strength gradually up to EA : MeOH $19: 1$ ). Yield $820 \mathrm{mg}$ (5.4 mmol, $21 \%$ ) of $N, 4$-dihydroxybenzamide (2a) as a colourless solid.

${ }^{1} \mathrm{H}$ NMR $\left(300 \mathrm{MHz}, \mathrm{DMSO}-d_{6}\right) \delta[\mathrm{ppm}]=10.97(\mathrm{~s}, 1 \mathrm{H}, \mathrm{NH})$, $9.96(\mathrm{~s}, 1 \mathrm{H}, \mathrm{Ar}-\mathrm{OH}), 8.84(\mathrm{~s}, 1 \mathrm{H}, \mathrm{NH}-\mathrm{OH}), 7.62\left(\mathrm{AA}^{\prime} \mathrm{BB}^{\prime}, 2 \mathrm{H}\right.$, $\left.H \mathrm{C}^{2,6}\right), 6.78\left(\mathrm{AA}^{\prime} \mathrm{BB}^{\prime}, 2 \mathrm{H}, H \mathrm{C}^{3,5}\right)$
${ }^{13} \mathrm{C}$ NMR (75 MHz, DMSO- $\left.d_{6}\right) \delta[\mathrm{ppm}]=164.48(\mathrm{C}=\mathrm{O})$, $160.12 \mathrm{C}^{1}, 128.81 \mathrm{C}^{2,6}, 123.40 \mathrm{C}^{4}, 114.98 \mathrm{C}^{3,5}$.

IR-ATR $\nu\left[\mathrm{cm}^{-1}\right]=3314 \mathrm{~m}, 3191 \mathrm{~m}, \mathrm{br}, 2923 \mathrm{w}, 1606 \mathrm{~s}(\mathrm{C}=\mathrm{O})$, 1570 s, 1534 m, 1493 m, 1457 m, 1457 m, 1350 m, 1316 m, 1263 s, 1128 vs. (C-O), 1177 m, 1157 vs., 1028 m, 971 m, 893 s, $848 v s ., 768 \mathrm{~s}$.

$R_{\mathrm{f}}(\mathrm{EA}: \mathrm{PE}=2: 1)=0.09$.

$\mathrm{Mp}: 146^{\circ} \mathrm{C}$.

(2b) 4-(5,5-dimethyl-1,4,2-dioxazol-3-yl)phenol. (2b) was prepared in a modified procedure based on the work of Couturier et al.. ${ }^{31}$ A dried $100 \mathrm{~mL}$ Schlenk flask was charged with $337 \mathrm{mg}$ (2.2 mmol, 1 eq.) N,4-dihydroxybenzamide (2b) and dried with $4 \mathrm{~mL}$ benzene under high vacuum. The solid residue was suspended in $50 \mathrm{~mL}$ of dry DCM (dried over $\mathrm{P}_{2} \mathrm{O}_{5}$, followed by distillation) and $872 \mathrm{mg}$ (6.6 mmol, 3 eq.) 2,2-diethoxypropane were added. To this suspension $511 \mathrm{mg}$ (2.2 mmol, 1 eq.) camphor sulfonic acid was added at once under argon atmosphere. After 105 minutes of stirring at room temperature the reaction was quenched by the addition of $10 \mathrm{~mL}$ saturated $\mathrm{NaHCO}_{3}$ solution. The mixture was stirred over night at room temperature and then the organic phase separated. The aqueous phase was extracted three times with $50 \mathrm{~mL}$ ether, and the combined organic phase dried using $\mathrm{Na}_{2} \mathrm{SO}_{4}$. After evaporation of all solvents in vacuo the residue was dissolved in THF and diethyl ether (to a final ratio of $1: 1)$ was added. 4-(5,5dimethyl-1,4,2-dioxazol-3-yl)phenol (2b) crystallized after days as colourless needles. Yield: $160 \mathrm{mg}(0.8 \mathrm{mmol}, 38 \%)$.

${ }^{1} \mathrm{H}$ NMR $\left(300 \mathrm{MHz}, \mathrm{DMSO}-d_{6}\right) \delta[\mathrm{ppm}]=7.65\left(\mathrm{AA}^{\prime} \mathrm{BB}^{\prime}, 2 \mathrm{H}\right.$, $\left.H \mathrm{C}^{3,5}\right), 6.89\left(\mathrm{AA}^{\prime} \mathrm{BB}^{\prime}, 2 \mathrm{H}, H \mathrm{C}^{2,6}\right), 1.68\left(\mathrm{~s}, 6 \mathrm{H}, \mathrm{CH}_{3}\right)$.

${ }^{13} \mathrm{C}$ NMR (75 MHz, DMSO- $\left.d_{6}\right) \delta[\mathrm{ppm}]=159.27 \mathrm{C}^{1}, 158.75$ $(\mathrm{C}=\mathrm{N}), 128.90 \mathrm{C}^{3,5}, 115.94 \mathrm{C}^{2,6}, 115.58 \mathrm{CCH}_{3}, 115.24 \mathrm{C}^{4}, 24.90$ $\mathrm{CH}_{3}$.

$$
R_{\mathrm{f}}(\mathrm{EA})=0.92 \text {. }
$$

Synthesis of benzylic hydroxamic acid functional initiator ( ${ }^{\text {benzyl }}$ HAA-OH) not employed for polymerization (3a-3b)

(3a) $N$-hydroxy-4-(hydroxymethyl)benzamide. The synthesis was carried out in a modified procedure based on the work of Hauser and Renfrow analogous to the synthesis of (1) $).^{37}$ Starting from $14.95 \mathrm{~g}$ (0.09 mol, 1 eq.) methyl 4-(hydroxymethyl) benzoate $11.28 \mathrm{~g}(0.068 \mathrm{~mol}, 75 \%)$ of $N$-hydroxy-4(hydroxymethyl)benzamide (3a) were obtained as a colourless solid.

${ }^{1} \mathrm{H}$ NMR (400 MHz, DMSO- $\left.d_{6}\right) \delta[\mathrm{ppm}]=11.08(\mathrm{~s}, 1 \mathrm{H}, \mathrm{N} H)$, 8.98 (s, $1 \mathrm{H}, \mathrm{NH}-\mathrm{OH}), 7.77-7.64\left(\mathrm{AA}^{\prime} \mathrm{BB}^{\prime}, 2 \mathrm{H}, \mathrm{HC}^{2,4}\right), 7.46-7.30$ $\left(\mathrm{AA}^{\prime} \mathrm{BB}^{\prime}, 2 \mathrm{H}, H \mathrm{C}^{3,5}\right), 5.28\left(\mathrm{t}, J=5.7 \mathrm{~Hz}, 1 \mathrm{H}, H \mathrm{O}-\mathrm{CH}_{2}\right), 4.53(\mathrm{~d}, J=$ $\left.5.7 \mathrm{~Hz}, 2 \mathrm{H}, \mathrm{CH}_{2}\right)$.

${ }^{13} \mathrm{C}$ NMR $\left(100 \mathrm{MHz}, \mathrm{DMSO}-d_{6}\right) \delta[\mathrm{ppm}]=164.54 C=\mathrm{O}$, 145.83 $\mathrm{C}^{4}, 131.10 \mathrm{C}^{1}, 126.70 \mathrm{C}^{2,4}, 126.10 \mathrm{C}^{3,5}, 62.4 \mathrm{~S} 4 \mathrm{CH}_{2}$.

(3b) (4-(5,5-dimethyl-1,4,2-dioxazol-3-yl)phenyl)methanol. The synthesis was carried out in a modified procedure based on the work of Couturier et al. analogous to the synthesis of $1 \mathbf{c} .^{31}$ Starting from $5.03 \mathrm{~g}(0.03 \mathrm{~mol}, 1$ eq. $) \quad N$-hydroxy-4(hydroxymethyl)benzamide $3.43 \mathrm{~g}$ (0.016 mol, 55\%) (4-(5,5dimethyl-1,4,2-dioxazol-3-yl)phenyl)methanol (3b) was obtained as a colourless liquid which solidified after one week at $-20{ }^{\circ} \mathrm{C}$. 
${ }^{1} \mathrm{H}$ NMR $\left(400 \mathrm{MHz}, \mathrm{DMSO}-d_{6}\right) \delta[\mathrm{ppm}]=7.72-7.59\left(\mathrm{AA}^{\prime} \mathrm{BB}^{\prime}\right.$, $\left.2 \mathrm{H}, H \mathrm{C}^{3,5}\right), 7.50-7.39\left(\mathrm{AA}^{\prime} \mathrm{BB}^{\prime}, 2 \mathrm{H}, H \mathrm{C}^{2,4}\right), 5.36(\mathrm{t}, J=5.7 \mathrm{~Hz}, 1 \mathrm{H}$, $\left.\mathrm{CH}_{2} \mathrm{OH}\right), 4.56$ (d, $\left.J=5.7 \mathrm{~Hz}, 2 \mathrm{H}, \mathrm{CH}_{2}\right), 1.63\left(\mathrm{~s}, 6 \mathrm{H}, \mathrm{CH}_{3}\right)$.

${ }^{13} \mathrm{C}$ NMR $\left(100 \mathrm{MHz}, \mathrm{DMSO}-d_{6}\right) \delta[\mathrm{ppm}]=157.49 \mathrm{C}=\mathrm{N}$, 146.58 $\mathrm{C}^{1}, 126.68 \mathrm{C}^{2,4}, 126.11 \mathrm{C}^{3,5}, 115.36 \mathrm{C}\left(\mathrm{CH}_{3}\right)_{2}, 62.36 \mathrm{CH}_{2}$, $24.41 \mathrm{CH}_{3}$.

$R_{\mathrm{f}}(\mathrm{EA}: \mathrm{PE}=1: 4)=0.35$.

Synthesis of aliphatic hydroxamic acid functional initiator not employed for polymerization $(4 a-4 b)$.

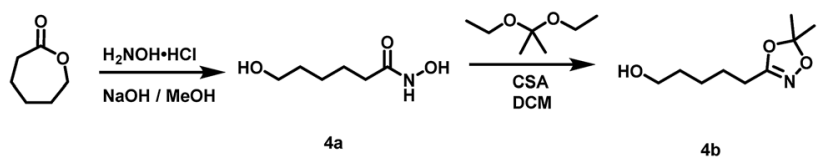

(4a) N,6-dihydroxyhexanamide. The synthesis was carried out in an modified procedure of Hauser and Renfrow. ${ }^{37}$ A $250 \mathrm{~mL}$ round bottom flask was charged with $17.12 \mathrm{~g}$ (150 mmol, 1.00 eq.) freshly distilled $\varepsilon$-caprolactone. In a separated flask $11.47 \mathrm{~g}$ (165 mmol, 1.1 eq.) $\mathrm{H}_{2} \mathrm{NOH} \cdot \mathrm{HCl}$ is dissolved in $65 \mathrm{~mL}$ methanol and neutralized with a solution of $12.62 \mathrm{~g}$ (225 mmol, $1.5 \mathrm{eq}$.) $\mathrm{KOH}$ in $32 \mathrm{~mL}$ methanol under shaking and cooling in a water bath. After 15 minutes the solution was filtered from precipitated $\mathrm{KCl}$ and added to the round bottom flask containing the caprolactone and stirred for 90 minutes. After the reaction had proceeded, the solution was acidified using conc. $\mathrm{HCl}$ to $\mathrm{pH} 4$ and reduced under vacuum until most of the product solidified. The residue was recrystallized twice from THF (approx. $200 \mathrm{~mL}$ ). $11.24 \mathrm{~g}$ (76 mmol, 51\%) N,6-dihydroxyhexanamide (4a) were recovered after crystallization for $72 \mathrm{~h}$ at $-20{ }^{\circ} \mathrm{C}$ as a colourless solid.

${ }^{1} \mathrm{H}$ NMR $\left(300 \mathrm{MHz}, \mathrm{DMSO}-d_{6}\right) \delta[\mathrm{ppm}]=10.37(\mathrm{~s}, 0.9 \mathrm{H}, \mathrm{N} H)$, $9.72 \mathrm{~s}(\mathrm{~s}, 0.1 \mathrm{H}, \mathrm{NH}), 9.03(\mathrm{~s}, 0.1 \mathrm{H}, \mathrm{NH}-\mathrm{OH}), 8.68(\mathrm{~s}, 0.9 \mathrm{H}, \mathrm{NH}-$ $\mathrm{OH}), 4.37\left(\mathrm{~s}, 1 \mathrm{H}, \mathrm{CH}_{2}-\mathrm{OH}\right), 3.35\left(\mathrm{t}, J=6.4 \mathrm{~Hz}, 2 \mathrm{H}, \mathrm{C}^{6} \mathrm{H}_{2}\right), 1.93(\mathrm{t}$, $\left.J=7.5 \mathrm{~Hz}, 2 \mathrm{H}, \mathrm{C}^{2} \mathrm{H}_{2}\right), 1.52-1.42\left(\mathrm{~m}, 2 \mathrm{H}, \mathrm{C}^{3} \mathrm{H}_{2}\right), 1.42-1.32(\mathrm{~m}, 2 \mathrm{H}$, $\left.\mathrm{C}^{5} \mathrm{H}_{2}\right), 1.30-1.16\left(\mathrm{~m}, 2 \mathrm{H}, \mathrm{C}^{4} \mathrm{H}_{2}\right)$.

${ }^{13} \mathrm{C}$ NMR $\left(75 \mathrm{MHz}, \mathrm{DMSO}-d_{6}\right) \delta[\mathrm{ppm}]=169.25 \mathrm{C}^{1}, 60.67 \mathrm{C}^{6}$, 32.42 $\mathrm{C}^{2}, 32.30 \mathrm{C}^{5}, 25.23 \mathrm{C}^{4}, 25.16 \mathrm{C}^{3}$.

IR-ATR $\nu\left[\mathrm{cm}^{-1}\right]=3311 \mathrm{~m}, 3205 \mathrm{~m}, 3029 \mathrm{~m}, 2932 \mathrm{~m}, 2858 \mathrm{~m}$ br, 1616 vs. $(\mathrm{C}=\mathrm{O}), 1544 \mathrm{~m}, 1449 \mathrm{~m}, 1466 \mathrm{~m}, 1362 \mathrm{~m}, 1274 \mathrm{~m}$, 1116 m, 1078 m, 1055 vs., 1012 vs., 977 vs., 785 m.

$R_{\mathrm{f}}(\mathrm{EA}: \mathrm{MeOH}=9: 1)=0.42$.

Mp: $84{ }^{\circ} \mathrm{C}$.

(4b) 5-(5,5-dimethyl-1,4,2-dioxazol-3-yl)pentan-1-ol. The synthesis of $\mathbf{4 b}$ was carried out analogous to the preparation of $\mathbf{1}$ on a scale of $4.27 \mathrm{~g}$ (29 mmol) N,6-dihydroxyhexanamide (4a). Purification was performed via column chromatography $\left(\mathrm{SiO}_{2}\right.$, $\mathrm{EA}: \mathrm{PE}=1: 1$ as eluent). Yield: $1.25 \mathrm{~g}$ (7 mmol, 23\%) 5-(5,5dimethyl-1,4,2-dioxazol-3-yl)pentan-1-ol (4b) as a colourless liquid.

${ }^{1} \mathrm{H}$ NMR $\left(300 \mathrm{MHz}, \mathrm{CDCl}_{3}\right) \delta[\mathrm{ppm}]=3.64(\mathrm{t}, J=6.3 \mathrm{~Hz}, 2 \mathrm{H}$, $\left.\mathrm{C}^{1} H_{2}\right), 2.31\left(\mathrm{t}, J=7.3 \mathrm{~Hz}, \mathrm{C}^{5} H_{2}\right), 1.76(\mathrm{~s}, 1 \mathrm{H}, \mathrm{OH}), 1.69-1.56(\mathrm{~m}$, $\left.4 \mathrm{H}, \mathrm{C}^{2} H_{2}, \mathrm{C}^{4} H_{2}\right), 1.55$ (s, 6H, $\left.\mathrm{CH}_{3}\right), 1.50-1.39\left(\mathrm{~m}, 2 \mathrm{H}, \mathrm{C}^{3} H_{2}\right)$.

${ }^{13} \mathrm{C}$ NMR $\left(75 \mathrm{MHz}, \mathrm{CDCl}_{3}\right) \delta[\mathrm{ppm}]=160.39 \mathrm{C}=\mathrm{N}, 114.54$ $C\left(\mathrm{CH}_{3}\right)_{2}, 62.65 \mathrm{C}^{1}, 32.26 \mathrm{C}^{2}, 25.22 \mathrm{C}^{3}, 25.18 \mathrm{C}^{4}, 24.91 \mathrm{CH}_{3}, 23.95$ $\mathrm{C}^{5}$.

$R_{\mathrm{f}}(\mathrm{EA}: \mathrm{PE}=1: 1)=0.46$.

\section{Polymerization procedures}

Synthesis of HAA-polyether (P1a-P6a) and deprotection to obtain the free hydroxamic acid functional polyether (P1bP6b).

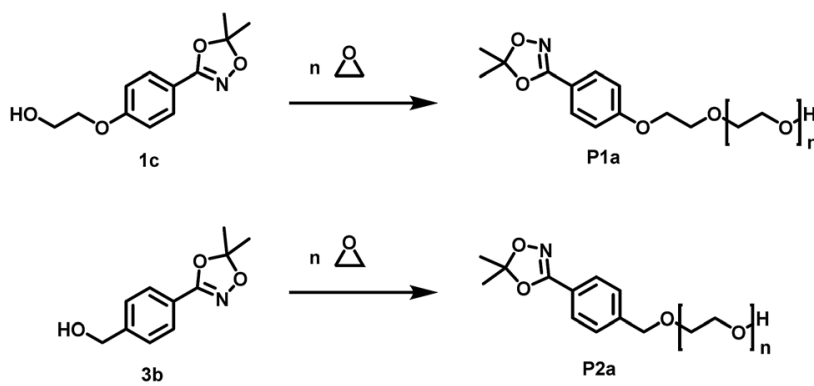

(P1a/P2a) synthesis of HAA-PEG and ${ }^{\text {benzyl } H A A-P E G \text {. Prepara- }}$ tion in example of HAA-OH as initiator. In a typical procedure, 2-(4-(5,5-dimethyl-1,4,2-dioxazol-3-yl)phenoxy)ethan-1-ol (1 eq.) (1d) was deprotonated by $90 \mathrm{~mol} \%$ cesium hydroxide monohydrate in $10 \mathrm{~mL}$ benzene in a $100 \mathrm{~mL}$ Schlenk flask. After stirring for 60 minutes at $50{ }^{\circ} \mathrm{C}$ under vacuum the solvents were removed with high vacuum $\left(10^{-3} \mathrm{mbar}\right)$ and subsequently the flask was heated to $60{ }^{\circ} \mathrm{C}$ overnight under high vacuum. The formed alkoxide salt was dissolved in $15 \mathrm{~mL}$ dry THF and $2 \mathrm{~mL}$ dry DMSO. EO was first distilled in the cold into a graduated ampoule and subsequently into the reaction flask containing the dissolved initiator. The mixture was heated to $50{ }^{\circ} \mathrm{C}$ and stirred for 2 days. Afterwards, $1 \mathrm{~mL}$ methanol was added to quench the reaction. Except for high boiling DMSO all residual solvents were removed in vacuo. The residue was diluted with $40 \mathrm{~mL}$ DCM and washed three times with $10 \mathrm{~mL}$ water. The organic phase was separated and dried using $\mathrm{Na}_{2} \mathrm{SO}_{4}$. The volume was reduced in vacuo to approx. $5 \mathrm{~mL}$ and the polymer precipitated in cold diethyl ether $\left(45 \mathrm{~mL},-20{ }^{\circ} \mathrm{C}\right.$, recovery through centrifugation at 4500 RPM for 10 minutes). Yields: 73$94 \%$.

${ }^{1} \mathrm{H}$ NMR $\left(400 \mathrm{MHz}, \mathrm{DMSO}-d_{6}\right) \delta[\mathrm{ppm}]=7.63\left(\mathrm{AA}^{\prime} \mathrm{BB}^{\prime}, 2 \mathrm{H}\right.$, $\left.\operatorname{ArC}^{3,5} H\right), 7.06\left(\mathrm{AA}^{\prime} \mathrm{BB}^{\prime}, 2 \mathrm{H}, \mathrm{ArC}^{2,6} H\right), 4.56(\mathrm{t}, J=5.5 \mathrm{~Hz}, 1 \mathrm{H}$, terminal $\mathrm{OH}), 4.19-4.11\left(\mathrm{~m}, 2 \mathrm{H}, \mathrm{Ar}-\mathrm{O}-\mathrm{CH}_{2}-\right)$, 3.79-3.71 (m, $2 \mathrm{H}$, Ar-O- $\mathrm{CH}_{2}-\mathrm{CH}_{2}-\mathrm{O}-$ ), 3.71-3.28 (m, polyether backbone), 1.61 (s, $\left.6 \mathrm{H}, \mathrm{CH}_{3}\right)$.

$(\mathbf{P 1 b} / \mathbf{P 2} \boldsymbol{b})$ removal of the acetal protecting group of $H A A-P E G$ (2a) to form HA-PEG.

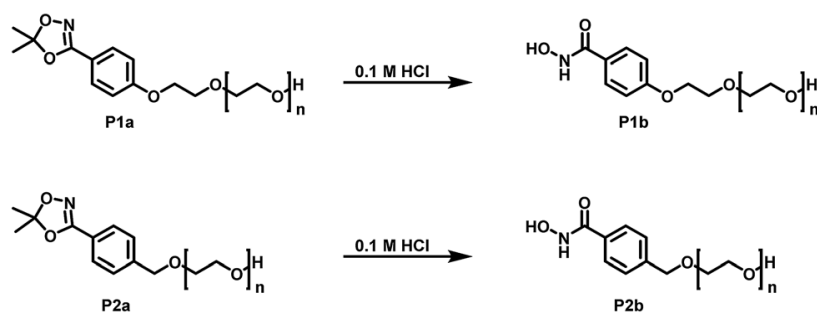

Preparation in example of HAA-PEG (P1a). In a typical procedure, $500 \mathrm{mg}$ HAA-PEG (P1a) were dissolved in $20 \mathrm{~mL}$ $0.1 \mathrm{M} \mathrm{HCl}$ and shaken for $24 \mathrm{~h}$. The polymer was recovered by adding $40 \mathrm{~mL}$ DCM and partitioning between the organic and 
aqueous phase. The organic phase was separated and dried over $\mathrm{Na}_{2} \mathrm{SO}_{4}$ and reduced in vacuo to a volume of approx. $5 \mathrm{~mL}$. After precipitation in ice cold diethyl ether $\left(45 \mathrm{~mL},-20{ }^{\circ} \mathrm{C}\right.$, recovery using centrifugation at 4500 RPM for 10 minutes), HA-PEG (P1b) was obtained in near quantitative ( $>98 \%)$ yields.

${ }^{1} \mathrm{H}$ NMR $\left(400 \mathrm{MHz}, \mathrm{DMSO}-d_{6}\right) \delta[\mathrm{ppm}]=11.06(\mathrm{~s}, 1 \mathrm{H}, \mathrm{N} H)$, $8.90(\mathrm{~s}, 1 \mathrm{H}, \mathrm{NH}-\mathrm{OH}), 7.72\left(\mathrm{AA}^{\prime} \mathrm{BB}^{\prime}, 2 \mathrm{H}, \mathrm{ArC}^{2,6} H\right), 6.99\left(\mathrm{AA}^{\prime} \mathrm{BB}^{\prime}\right.$, $\left.2 \mathrm{H}, \mathrm{ArC}^{3,5} H\right), 4.57(\mathrm{t}, J=5.5 \mathrm{~Hz}, 1 \mathrm{H}$, terminal $\mathrm{OH}), 4.19-4.08(\mathrm{~m}$, 2H, Ar-O- $\mathrm{CH}_{2}-$ ), 3.79-3.72 (m, 2H, Ar-O- $\left.\mathrm{CH}_{2}-\mathrm{CH}_{2}-\mathrm{O}-\right)$, 3.733.37 (m, polyether backbone).

(P3a, P4a, P5a, P6a) synthesis of HAA-PPO, HAA-PEEGE, ben${ }^{z y l}$ HAA-PPO, ${ }^{\text {benzyl }} H A A-P E E G E$. Preparation example of HAA-PPO with $\mathrm{HAA}-\mathrm{OH}$ as an initiator. In a typical procedure 2-(4-(5,5dimethyl-1,4,2-dioxazol-3-yl)phenoxy)ethan-1-ol (1 eq.) (1d) was deprotonated by $90 \mathrm{~mol} \%$ cesium hydroxide monohydrate in $10 \mathrm{~mL}$ in a $25 \mathrm{~mL}$ Schlenk flask. After stirring for 60 minutes at $50{ }^{\circ} \mathrm{C}$ under vacuum the solvents were removed with high vacuum $\left(10^{-3} \mathrm{mbar}\right)$ and subsequently the flask heated to $60{ }^{\circ} \mathrm{C}$ overnight under high vacuum. $1 \mathrm{~mL}$ dry propylene oxide (dried via cryo-distillation over $\mathrm{CaH}_{2}$ ) were added to the formed alkoxide using a syringe and the polymerization was performed at $40{ }^{\circ} \mathrm{C}$ under vacuum overnight. Subsequently, $1 \mathrm{~mL}$ methanol was added to quench the reaction and the polymer was dissolved in $40 \mathrm{~mL}$ DCM and washed three times with $10 \mathrm{~mL}$. The organic phase was separated, dried using $\mathrm{Na}_{2} \mathrm{SO}_{4}$ and all solvents were evaporated in vacuo. Typical yield: $78-95 \%$ as highly viscous amorphous polymer.

Preparation of PEEGE polymers was carried out analogously.

${ }^{1} \mathrm{H}$ NMR $\left(300 \mathrm{MHz}, \mathrm{CDCl}_{3}\right) \delta[\mathrm{ppm}]=7.70\left(\mathrm{AA}^{\prime} \mathrm{BB}^{\prime}, 2 \mathrm{H}\right.$, $\left.\mathrm{ArC}^{3,5} \mathrm{H}\right), 6.94\left(\mathrm{AA}^{\prime} \mathrm{BB}^{\prime}, 2 \mathrm{H}, \mathrm{ArC}^{2,6} H\right), 4.19-4.11$ (m, 2H, Ar-O$\mathrm{CH}_{2}-$ ) 4.16 (m, 2H, Ar-O- $\mathrm{CH}_{2}-\mathrm{CH}_{2}-\mathrm{O}-$ ), 3.85 (m, 2H, Ar-O$\mathrm{CH}_{2}-\mathrm{CH}_{2}-\mathrm{O}-$ ), 3.69-3.28 (m, polyether backbone), 1.66 (s, 6H, $\left.\mathrm{C}\left(\mathrm{CH}_{3}\right)_{2}\right), 1.34-1.08$ (m, propylene oxide $\left.\mathrm{CH}_{3}\right)$.

(P6b) cleavage of the protection groups of HAA-PEEGE to obtain HA-linPG (linear polyglycerol). $50 \mathrm{mg}$ of HAA-PEEGE (P6a) were dissolved in $10 \mathrm{~mL}$ isopropanol and $200 \mathrm{mg}$ DOWEX 50WX8 acidic ion exchange resin were added. The mixture was shaken for 2 days and filtered afterwards. The resin was washed with $5 \mathrm{~mL}$ isopropanol and $5 \mathrm{~mL}$ methanol, and the combined organic phases were evaporated in vacuo to obtain $41 \mathrm{mg}$ (81\%) of HA-linPG (P6b) as yellowish amorphous polymer.

Cleavage of the protecting group of P3a, P4a and P5a was carried out analogous.

${ }^{1} \mathrm{H}$ NMR $\left(300 \mathrm{MHz}, \mathrm{DMSO}-d_{6}\right) \delta[\mathrm{ppm}]=11.07(\mathrm{~s}, 1 \mathrm{H}, \mathrm{N} H)$, $7.70\left(\mathrm{AA}^{\prime} \mathrm{BB}^{\prime}, 2 \mathrm{H}, \mathrm{ArC}^{2,6} H\right), 6.99\left(\mathrm{AA}^{\prime} \mathrm{BB}^{\prime}, 2 \mathrm{H}, \mathrm{ArC}^{3,5} H\right), 4.19-4.04$ (m, 2H, Ar-O- $\mathrm{CH}_{2}-$ ), 3.72-3.13 (m, polyether backbone).

\section{Nanoparticle modification}

Coating of $\mathrm{FeO}_{\boldsymbol{x}}$ nanoparticles with HA-PEG. In a typical procedure, $10 \mathrm{mg}$ HA-PEG (P1b) were dissolved in $5 \mathrm{~mL}$ DCM. $3 \mathrm{mg}$ oleate-coated $\mathrm{FeO}_{x}$ nanoparticles were dissolved in DCM as well and added slowly to the polymer solution. The suspension was shaken overnight and precipitated in ice-cold diethyl ether $\left(15 \mathrm{~mL},-20{ }^{\circ} \mathrm{C}\right.$, recovery through centrifugation at 4500 RPM for 15 minutes). After redissolving in DCM the magnetic nanoparticles were washed by concentrating the nanoparticles with a strong neodymium magnet at the bottom of a flask and subsequent decantation of the supernatant. For DLS measurements the nanoparticles were redissolved in DCM and sterile filtered. For TEM measurement water was used for redissolving instead.

\section{Conflicts of interest}

There are no conflicts to declare.

\section{Acknowledgements}

T. J. acknowledges a fellowship by the Max Planck Graduate Center. The authors thank Monika Schmelzer for SEC measurements, Tatjana Dänzer for TEM measurement, Thi Dinh for experimental assistance and Jan Hilgert for providing $\mathrm{FeO}_{x}$ nanoparticles.

\section{Notes and references}

1 E. Faure, C. Falentin-Daudré, C. Jérôme, J. Lyskawa, D. Fournier, P. Woisel and C. Detrembleur, Prog. Polym. Sci., 2013, 38, 236.

2 (a) E. J. Werner, J. Kozhukh, M. Botta, E. G. Moore, S. Avedano, S. Aime and K. N. Raymond, Inorg. Chem., 2009, 48, 277; (b) S. M. Cohen, B. O'Sulliva and K. N. Raymond, Inorg. Chem., 2000, 39, 4339; (c) J. Xu, T. M. Corneillie, E. G. Moore, G.-L. Law, N. G. Butlin and K. N. Raymond, J. Am. Chem. Soc., 2011, 133, 19900.

3 N. Patil, C. Jérôme and C. Detrembleur, Prog. Polym. Sci., 2018, 82, 34.

4 M. Yu, J. Hwang and T. J. Deming, J. Am. Chem. Soc., 1999, $121,5825$.

5 (a) B. P. Lee, J. L. Dalsin and P. B. Messersmith, Biomacromolecules, 2002, 3, 1038; (b) B. P. Lee, P. B. Messersmith, J. N. Israelachvili and J. H. Waite, Annu. Rev. Mater. Res., 2011, 41, 99; (c) T. Gillich, E. M. Benetti, E. Rakhmatullina, R. Konradi, W. Li, A. Zhang, A. D. Schlüter and M. Textor, J. Am. Chem. Soc., 2011, 133, 10940; (d) N. Holten-Andersen, M. J. Harrington, H. Birkedal, B. P. Lee, P. B. Messersmith, K. Y. C. Lee and J. H. Waite, Proc. Natl. Acad. Sci. U. S. A., 2011, 108, 2651; (e) U. S. Schubert and C. Eschbaumer, Angew. Chem., Int. Ed. Engl., 2002, 41, 2892; (f) P. R. Andres and U. S. Schubert, Adv. Mater., 2004, 16, 1043.

6 (a) K. Niederer, C. Schüll, D. Leibig, T. Johann and H. Frey, Macromolecules, 2016, 49, 1655; (b) V. S. Wilms, H. Bauer, C. Tonhauser, A.-M. Schilmann, M.-C. Müller, W. Tremel and H. Frey, Biomacromolecules, 2013, 14, 193.

7 G. Schwarzenbach and K. Schwarzenbach, Helv. Chim. Acta, 1963, 46, 1390.

8 Y. K. Agrawal and S. G. Tandon, J. Inorg. Nucl. Chem., 1972, 34, 1291.

9 J. P. Folkers, C. B. Gorman, P. E. Laibinis, S. Buchholz, G. M. Whitesides and R. G. Nuzzo, Langmuir, 1995, 11, 813. 10 J. B. Neilands, Science, 1967, 156, 1443. 
11 (a) R. Codd, Coord. Chem. Rev., 2008, 252, 1387; (b) B. Kurzak, H. Kozłowski and E. Farkas, Coord. Chem. Rev., 1992, 114, 169.

12 L. Bauer and O. Exner, Angew. Chem., Int. Ed. Engl., 1974, 13, 376.

13 (a) A. Vannini, C. Volpari, G. Filocamo, E. C. Casavola, M. Brunetti, D. Renzoni, P. Chakravarty, C. Paolini, R. de Francesco, P. Gallinari, C. Steinkühler and S. Di Marco, Proc. Natl. Acad. Sci. U. S. A., 2004, 101, 15064; (b) C. J. Marmion, D. Griffith and K. B. Nolan, Eur. J. Inorg. Chem., 2004, 2004, 3003.

14 US2402604A, 1946.

15 (a) J. W. Rosthauser and A. Winston, Macromolecules, 1981, 14, 538; (b) A. Winston and D. Kirchner, Macromolecules, 1978, 11, 597; (c) A. Winston and G. R. McLaughlin, J. Polym. Sci., Polym. Chem. Ed., 1976, 14, 2155; (d) D. V. P. R. Varaprasad, J. W. Rosthauser and A. Winston, J. Polym. Sci., Polym. Chem. Ed., 1984, 22, 2131.

16 A. Winston and E. T. Mazza, J. Polym. Sci., Polym. Chem. Ed., 1975, 13, 2019.

17 Y. K. Agrawal, H. Kaur and S. K. Menon, React. Funct. Polym., 1999, 39, 155.

18 T. Hirotsu, S. Katoh, K. Sugasaka, M. Sakuragi, K. Ichimura, Y. Suda, M. Fujishima, Y. Abe and T. Misonoo, J. Polym. Sci., Polym. Chem. Ed., 1986, 24, 1953.

19 F. A. Alakhras, K. A. Dari and M. S. Mubarak, J. Appl. Polym. Sci., 2005, 97, 691.

20 (a) P. N. Sophiamma and K. Sreekumar, React. Funct. Polym., 1997, 35, 169; (b) M. Narita, T. Teramoto and M. Okawara, Bull. Chem. Soc. Jpn., 1972, 45, 3149.

21 (a) W. Kern and R. C. Schulz, Angew. Chem., 1957, 69, 153; (b) A. Domb, E. Cravalho and R. Langer, J. Polym. Sci., Polym. Chem. Ed., 1988, 26, 2623.

22 R. S. Mello, E. S. Orth, W. Loh, H. D. Fiedler and F. Nome, Langmuir, 2011, 27, 15112.

23 (a) M. Imran ul-haq, J. L. Hamilton, B. F. L. Lai, R. A. Shenoi, S. A. Horte, I. Constantinescu, H. A. Leitch and
J. N. Kizhakkedathu, ACS Nano, 2013, 7, 10704; (b) J. L. Hamilton and J. N. Kizhakkedathu, Molecular and Cellular Therapies, 2015, 3, 3; (c) N. A. A. Rossi, I. Mustafa, J. K. Jackson, H. M. Burt, S. A. Horte, M. D. Scott and J. N. Kizhakkedathu, Biomaterials, 2009, 30, 638.

24 C. J. Adams, J. J. Wilson and E. Boros, Mol. Pharmaceutics, 2017, 14, 2831.

25 G. M. Iskander, H. M. Kapfenstein, T. P. Davis and D. E. Wiley, J. Appl. Polym. Sci., 2000, 78, 751.

26 J. Herzberger, K. Niederer, H. Pohlit, J. Seiwert, M. Worm, F. R. Wurm and H. Frey, Chem. Rev., 2016, 116, 2170.

27 S. R. Sandler and W. Karo, Organic functional group preparations, Acad. Press, Orlando, 1989, vol. 12.

28 D. Geffken and J. Froböse, J. Prakt. Chem., 1994, 336, 550.

29 (a) J. Lim, Y. Song, J.-H. Jang, C.-H. Jeong, S. Lee, B. Park and

Y. H. Seo, Arch. Pharmacal Res., 2018, 41, 967; (b)

E. Orlowska, A. Roller, H. Wiesinger, M. Pignitter, F. Jirsa, R. Krachler, W. Kandioller and B. K. Keppler, RSC Adv., 2016, 6, 40238; (c) B. M. R. Liénard, L. E. Horsfall, M. Galleni, J.-M. Frère and C. J. Schofield, Bioorg. Med. Chem. Lett., 2007, 17, 964.

30 D. Cerniauskaite, J. Rousseau, A. Sackus, P. Rollin and A. Tatibouët, Eur. J. Org. Chem., 2011, 2011, 2293.

31 M. Couturier, J. L. Tucker, C. Proulx, G. Boucher, P. Dubé,

B. M. Andresen and A. Ghosh, J. Org. Chem., 2002, 67, 4833. 32 D. Geffken and J. Froböse, J. Prakt. Chem., 1993, 335, 555. 33 M. Schömer and H. Frey, Macromolecules, 2012, 45, 3039.

34 (a) M. Hans, H. Keul and M. Moeller, Polymer, 2009, 50, 1103;

(b) A. Thomas, S. S. Müller and H. Frey, Biomacromolecules, 2014, 15, 1935.

35 B. E. Bierer and D. G. Nathan, Blood, 1990, 76, 2052.

36 T. Yoshino, S. Inaba and Y. Ishido, Bull. Chem. Soc. Jpn., 1973, 46, 553.

37 C. R. Hauser and W. B. Renfrow Jr, Org. Synth., 1939, 19, 15. 38 A. Jeanrenaud, Ber. Dtsch. Chem. Ges., 1889, 22, 1270. 